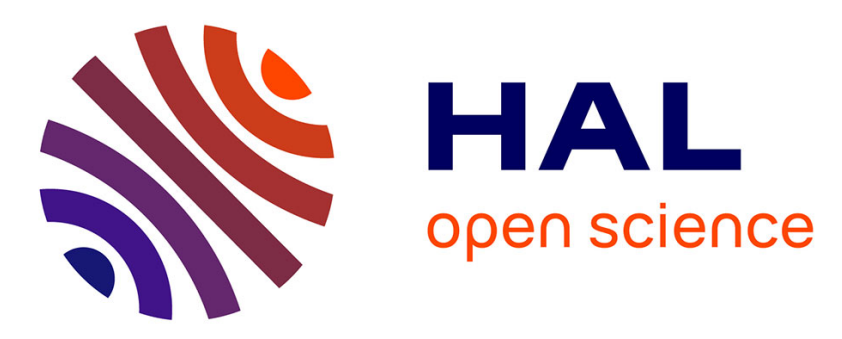

\title{
Recherches archéologiques sur les mines et la métallurgie de l'argent à Imiter (Maroc)
}

François-Xavier Fauvelle, Caroline Robion-Brunner, Jean-Marc Fabre, Sandrine Baron, Romain Mensan, Mustapha Souhassou

\section{To cite this version:}

François-Xavier Fauvelle, Caroline Robion-Brunner, Jean-Marc Fabre, Sandrine Baron, Romain Mensan, et al.. Recherches archéologiques sur les mines et la métallurgie de l'argent à Imiter (Maroc). Journal of African archaeology, 2021, 19 (1), pp.90-113. 10.1163/21915784-20210002 . hal-03176019

\section{HAL Id: hal-03176019 \\ https://hal-univ-tlse2.archives-ouvertes.fr/hal-03176019}

Submitted on 15 Nov 2021

HAL is a multi-disciplinary open access archive for the deposit and dissemination of scientific research documents, whether they are published or not. The documents may come from teaching and research institutions in France or abroad, or from public or private research centers.
L'archive ouverte pluridisciplinaire HAL, est destinée au dépôt et à la diffusion de documents scientifiques de niveau recherche, publiés ou non, émanant des établissements d'enseignement et de recherche français ou étrangers, des laboratoires publics ou privés. 


\title{
Recherches archéologiques sur les mines et la métallurgie de l'argent à Imiter (Maroc)
}

François-Xavier Fauvelle

Collège de France, Paris, France

TRACES - UMR 5608, Université Jean Jaurès, Toulouse, France

Caroline Robion-Brunner

TRACES - UMR 5608, Université Jean Jaurès, Toulouse, France caroline.robion@univ-tlse2.fr

Jean-Marc Fabre

TRACES - UMR 5608, Université Jean Jaurès, Toulouse, France

Sandrine Baron

TRACES - UMR 5608, Université Jean Jaurès, Toulouse, France

Romain Mensan

TRACES - UMR 5608, Université Jean Jaurès, Toulouse, France

Mustapha Souhassou

TRACES - UMR 5608, Université Jean Jaurès, Toulouse, France

Ibn Zohr University, Faculté Polydisciplinaire de Taroudant, Taroudant, Morocco

\begin{abstract}
Imiter, mine d'argent de l'Anti-Atlas marocain encore en activité, possède des vestiges archéologiques de travaux miniers et métallurgiques. L'étude de textes anciens et d'artefacts a permis de la rapprocher de la mine d'argent de Todgha connue à l'époque médiévale (El Ajlaoui 1994). Entre 2011 et 2014, une équipe pluridisciplinaire (historien, géologue métallogéniste, géochimiste, archéologues) a entrepris des prospections en surface et en souterrain, la fouille de trois cuves de traitement du minerai ainsi que la caractérisation
\end{abstract}


minéralogique et géochimique de minerais et déchets métallurgiques anciens. Les résultats des datations des cuves placent le dépôt après utilisation entre le IIe siècle cal $\mathrm{BC}$ et le Ve siècle cal $\mathrm{AD}$, soit avant la période islamique. Cet article fait état des résultats de ces recherches, qui documentent pour la première fois une exploitation antique de l'argent dans les régions méridionales du Maroc, exploitation qui s'est poursuivie à l'époque médiévale.

Imiter, the silver mine of the Moroccan Anti-Atlas still in operation today, displays archaeological evidence of ancient mining and metallurgical works. Written sources and the study of artefacts has already allowed to suggest that the site of Imiter was the ancient Todgha, a locality mentioned during the medieval period (El Ajlaoui 1994). Between 2011 and 2014, a multidisciplinary team (historian, metallogenic geologist, geochemist, archaeologists) undertook surface and underground prospection, the excavation of three ore enrichment tanks as well as the mineralogical and geochemical characterization of ancient ores and metallurgical wastes. The radiocarbon dates obtained on the tanks place their final use between the 2 nd century cal BC and the 5th century cal AD, i.e. before the Islamic period. This article reports on results of this research, which documents for the first time an ancient silver mining site in the southern regions of Morocco, which continued in medieval times.

\section{Keywords}

Maroc, argent, mine d'argent, métallurgie, archéologie islamique, géochimie des métaux Morocco, silver, silver mine, metallurgy, Islamic archaeology, geochemistry of metals 


\section{Introduction}

De 2011 à 2014, en marge du programme archéologique « Sijilmâsa (Maroc): ville, oasis, carrefour » dévolu à la fouille de la cité islamique de Sijilmâsa ${ }^{1}$, un volet paléométallurgique s'est donné pour objectif d'étudier la production des métaux dans l'environnement de la ville médiévale. Des prospections menées par une équipe pluridisciplinaire ont ainsi été conduites jusqu'à une centaine de kilomètres de rayon autour du site archéologique de Sijilmâsa et ont fait l'objet, le cas échéant, d'analyses géologiques, minéralogiques, géochimiques, et d'opérations archéologiques (Milot et al. 2018; Baron et al. 2020). L'ambition de ce volet de recherche était double: d'une part documenter la dimension « industrielle » de la relation de Sijilmâsa à son paysage; d'autre part s'émanciper du paradigme historique qui a longtemps indexé le destin de Sijilmâsa (et plus généralement des villes islamiques de la bordure septentrionale du Sahara) aux aléas du commerce de l'or venu des régions ouest-africaines (Devisse 1990). De fait, si les témoins matériels (autres que numismatiques) de l'importation et de la transformation de l'or ouest-africain sont encore rares au Maroc (comme d'ailleurs plus généralement au nord du Sahara), en revanche les traces matérielles de l'exploitation et de l'élaboration locales de l'argent et du cuivre dans le Maroc pré-saharien sont nombreuses (Rosenberger 1970a, 1970b; El Ajlaoui 2008), apportant de ce fait un renfort matériel aux indications des sources écrites (Colin 1936, 1954). Les résultats présentés dans cet article contribuent à accroître la documentation au sujet de l'activité ancienne d'extraction et d'élaboration de l'argent sur le site d'Imiter, mine célèbre et encore en activité de l'Anti-Atlas oriental. Ils permettent de confirmer la localisation d'ateliers liés à la production de l'argent, de déterminer les différents minerais exploités, de caractériser les techniques d'extraction, de traitement (broyage, débourbage, lavage, enrichissement...) et de réduction, et enfin de déterminer les dates d'exploitation (Fig. 1).

Contrairement à la métallurgie du fer, la métallurgie du plomb argentifère ou des métaux non ferreux en général laisse peu de traces en termes de structures archéologiques et de déchets. En effet, le plus souvent, pour les périodes anciennes, les scories (déchets issues de la réduction d'un minerai, ici argentifère) étaient retraitées afin d'en extraire au maximum le métal restant ou étaient transformées en verre au plomb pour d'autres usages (Wedepohl et al. 1995; Gratuze et al. 2017). À la période contemporaine, les sociétés minières ont, quant à

\footnotetext{
${ }^{1}$ Programme dirigé par Elarbi Erbati et François-Xavier Fauvelle. Sur les résultats des fouilles, voir Fauvelle et al. 2014, 2018; Fauvelle 2018. La monographie des fouilles est en cours de publication.
} 
elles, souvent retraité les dernières scories anciennes restées sur place afin d'en récupérer, à l'aide de procédés beaucoup plus efficaces, les métaux (plomb et surtout argent). En Europe occidentale, par exemple, d'importants sites de plomb argentifère n'ont livré parfois qu'un ou deux seaux de déchets, alors que des quantités très importantes de métal ont été produites, comme c'est le cas pour les mines d'argent médiévales carolingiennes, à Melle, en France (Tereygeol 2001). À cet égard, le site d'Imiter est exceptionnel. Outre la préservation d'une grande partie de la chaîne opératoire de l'argent, l'originalité même des minerais exploités (argent natif, amalgamé ou non au mercure, divers types de sulfures d'argent dont la galène argentifère et l'imitérite) présente un intérêt majeur. Ces évidences archéologiques sont encore repérables et ont d'ailleurs permis leur redécouverte moderne et la remise en exploitation du site.

\section{Imiter d'hier à aujourd'hui}

Dans la littérature scientifique, Imiter est souvent considéré comme une mine « ancienne » par les chercheurs (Rosenberger 1970a, 1970b; El Ajlaoui 1994) et les géologues de la mine (Amade 1963; Grappe 1976). S’appuyant sur des données issues des sources écrites, El Ajlaoui a, de façon convaincante, identifié Imiter à la mine d'argent de Todgha, célèbre durant la période idrisside (fin du VIIIe-fin du Xe siècle CE). Un précieux auteur andalou du XIe siècle, al-Bakrî, écrit: « La ville de Sijilmâsa fut fondée en 140 H (757 CE). Sa naissance entraîna l'évacuation de la ville de Todgha, à deux jours de marche de là, ainsi que la ruine de la ville de Zîz » (Monteil 1968: 42). Cette mention permet de lier le destin des deux cités. Elle donne l'antériorité chronologique à Todgha et laisse supposer que celle-ci a décliné en tant que centre politique lorsque Sijilmâsa a émergé au milieu du VIIIe siècle. Elle n'implique pas, cependant, l'abandon de la fonction industrielle du site, dont on peut au contraire supposer qu'elle passe alors sous le contrôle de la cité du Tafilalet. La relation entre émergence de la cité islamique et exploitation du paysage minier a souvent été rappelée, par exemple au regard du site de Tamdult dans la vallée du Draa (Cressier et al. 2001; Cressier 2004), site du reste beaucoup mieux préservé qu'Imiter car il n'a pas connu de reprise d'activité moderne. À Zgounder également, autre site marocain où l'argent fut exploité aux XIIe-XIIIe siècles (Colin 1954), les vestiges miniers s'accompagnent des restes d'une ville située sur la rive opposée de l'oued où se rencontrent les vestiges métallurgiques (El Ajlaoui 2008: 47-51).

El Ajlaoui a décrit les vestiges archéologiques repérés à Imiter lors de sa visite du site dans les années 1980: une aire de traitement du minerai constituée de centaines de meules, de 
nombreuses cuvettes, une aire d'extraction et de transformation du métal avec des vestiges de fours et des creusets, ainsi que des travaux miniers s'étendant sur plusieurs kilomètres et des vestiges d'habitat fortifiés ainsi que du mobilier céramique et vitreux. Les descriptions précises d'El Ajlaoui $(1994,2008)$ ont été un véritable vadémécum pour nos propres recherches. Cet auteur a également dressé une carte des vestiges à partir de ses observations (Fig. 2). En dépit de nos efforts, nous avons cependant été obligés de constater le fort décalage qualitatif, à l'avantage de la première, entre la carte d'El Ajlaoui et la nôtre (Fig. 3). Ce décalage provient des profondes perturbations qu'a connues le paysage au cours des dernières décennies, au point que les aspects les plus remarquables de la morphologie du site (oued, pendages naturels et reliefs) sont devenus méconnaissables, et que nombre de vestiges semblent avoir disparu ou être recouverts. Il ne nous a, par exemple, pas été possible de repérer les vestiges d'habitats fortifiés évoqués par El Ajlaoui.

La raison de cette évolution tient au fait que le site est aujourd'hui situé dans une concession minière en exploitation ${ }^{2}$. Dans le contexte minier actuel, la mine d'Imiter fait figure d'exception: c'est la seule exploitation au monde qui ne produit que de l'argent et en quantité importante. Le gisement a été redécouvert dans les années 1950, à partir de photographies aériennes où apparaissaient les anciens travaux miniers et les haldes ${ }^{3}$. La première phase d'exploitation moderne, de 1963 à 1978, a simplement consisté à retraiter les stériles laissés par les Anciens. Ceux-ci, particulièrement volumineux et riches en argent, ont assuré le succès de l'entreprise. Grappe (1976) estimait la quantité des haldes à 525000 tonnes, avec une teneur de $350 \mathrm{~g} / \mathrm{t}$ d'argent correspondant à 184 tonnes d'argent métal. Mais, d'après les informations orales fournies par le Service Géologique de la mine, le volume des haldes traitées aurait été plus important, s'élevant à 700000 tonnes de tout-venant titrant en moyenne à $500 \mathrm{~g} / \mathrm{t}$ d'argent, soit 350 tonnes d'argent métal. Cela laisse imaginer la richesse en argent du site au moment de son exploitation aux périodes plus anciennes. La deuxième phase d'exploitation moderne, commencée en 1978, et toujours en cours, a consisté en la reprise d'extraction du minerai, en carrière et en souterrain, suivant un rythme assez soutenu. La production moyenne actuelle est de 250 tonnes d'argent par an (ce qui place la mine au 10e rang mondial en termes de volume) et l'exploitant a programmé une très nette augmentation dans les prochaines années. C'est cette reprise d'exploitation, impliquant de très importants travaux de surface (ouverture de carrières à ciel ouvert, construction

\footnotetext{
${ }^{2}$ Exploitation de la Société métallurgique d'Imiter du groupe Managem.

${ }^{3}$ C'est-à-dire les déblais considérés comme stériles par les anciens mineurs.
} 
d'infrastructures et déplacements de haldes) et le remodelage du relief, qui explique la profonde transformation du paysage entre les précieuses observations d'El Ajlaoui et les nôtres.

\section{Conditions et limites de l'étude, méthodologie}

Si l'exploitation actuelle de la mine a eu un impact sur la conservation et la visibilité des vestiges de surface, en revanche les géologues rencontrés lors de chaque visite nous ont tous dit que l'exploitation actuelle évitait, pour des raisons de sécurité, les anciens travaux miniers. Ainsi, en souterrain, le travail d'extraction, qui se fait en remontant, est habituellement stoppé aux environs de la cote $-80 \mathrm{~m}$. Dès lors, certains secteurs intensivement exploités par les Anciens ont été délaissés lors de la reprise d'exploitation. Cette pratique, dictée par les impératifs de l'exploitation, laisse augurer d'une relativement bonne conservation des travaux miniers anciens sur une grande partie du site, en dehors du périmètre des carrières. Signalons enfin que du mobilier lié à la métallurgie ancienne est conservé au Service Géologique et dans le bâtiment de la direction de la mine. Il s'agit de plusieurs meules, d'un fragment de creuset et de quelques rares scories.

Les limites de notre étude ont été dictées par les contraintes de l'exploitation actuelle. Nous n'avons ainsi pu réaliser que trois courtes missions de quelques jours seulement en 2011, 2012 et $2014^{4}$. Autorisés par la société exploitante, les observations, prélèvements et brèves opérations archéologiques ont été réalisés sans certitude de revoir les vestiges dans le futur. Ces conditions ont pu, dans certains cas, limiter la qualité de l'enregistrement des données. Nous avons cependant, autant que possible, déployé une approche pluridisciplinaire. L'approche archéologique visait à recenser, décrire, interpréter et si possible dater les vestiges matériels des phases d'extraction et de traitement du minerai: anciens puits, zones de concassage et tri du minerai, structures de lavage et d'enrichissement, fourneaux permettant d'extraire le métal. L'approche microscopique visait à caractériser, par la pétrographie et la minéralogie, les minerais extraits par les Anciens. L'objectif était d'identifier le ou les type(s) de minerai(s) exploité(s) par les Anciens. L'approche géochimique avait pour objectif d'attribuer une signature isotopique de certains minerais, de scories anciennes retrouvées sur

\footnotetext{
${ }^{4}$ Mission du 17 au 22 octobre 2011: équipe constituée de Sandrine Baron, Jean-Marc Fabre, Caroline Robion-Brunner (responsable de la mission) et Mustapha Souhassou. Mission du 8 au 13 mai 2012: mêmes participants. Mission du 23 au 25 mai 2014: équipe constituée de Sandrine Baron, FrançoisXavier Fauvelle (responsable de la mission), Romain Mensan, Jean Milot et Mustapha Souhassou.
} 
le site, de parois de fours et aussi du métal produit (billes de métal incluses dans la matrice silicatée des scories).

Imiter livre des vestiges anciens de toutes les étapes de l'élaboration de l'argent, depuis l'extraction minière jusqu'à la coulée de billes de métal en creusets (Fig. 3). Cette observation, rare sur le terrain, justifie que nous présentions nos observations archéologiques en suivant la chaîne opératoire de l'élaboration de l'argent.

\section{La chaîne opératoire de l'argent à Imiter}

\section{L'extraction}

El Ajlaoui signale, à Imiter, trois zones principales d'extraction minière ancienne, qu'il appelle respectivement Carrière A, Borne 8 et Borne 3 (1994: 14). La localisation de la Carrière A sur sa carte nous permet de penser qu'il s'agit du secteur que nous appelons, avec les géologues actuels, « Carrière des Anciens ». La Borne 8 est localisée avec une quasicertitude. Si ces deux points sont fiables, alors il nous faut constater la disparition probable de nombreux travaux vus par El Ajlaoui: ceux de la Borne 3 seraient en effet situés à l'emplacement d'infrastructures actuelles qui ont complètement remanié la topographie; quant aux vestiges de bâtiments associés par El Ajlaoui à la ville de Todgha, ils étaient probablement situés à l'emplacement actuel d'une gigantesque accumulation de haldes modernes et d'un glacis arasé par les tractopelles. Nous avons cependant pu effectuer des observations complémentaires de celles d'El Ajlaoui. Quatre secteurs, où les vestiges sont remarquables, ont retenus notre attention. Il s'agit de la «Carrière des Anciens » et d'une série de puits alignés selon un axe nord-sud, qui devaient être en relation avec cette dernière et servir de galerie d'exhaure; des travaux d'extraction situés sur le filon Sud 1, à proximité des puits actuels PF et P4 (désignations de l'exploitant); de la carrière B8 (désignation de l'exploitant, correspondant à la Borne 8 d'El Ajlaoui; Fig. 3), à l'extrémité Est; enfin, d'une série de petits puits (en-dehors de la carte) située un peu à l'écart des filons principaux, vers le sud.

La carrière des Anciens se présente aujourd'hui comme une vaste exploitation à ciel ouvert, de même orientation (E-W) que la structure hébergeant les minéralisations principales, d'environ $350 \mathrm{~m}$ de long, $50 \mathrm{~m}$ de large et une trentaine de mètres de profondeur (Fig. 4b). Selon les indications de l'exploitant, le secteur n'a pas été retouché à une époque récente. Cependant, une visite dans la partie inférieure des travaux permet de repérer de nombreux trous de foret, qui indiquent une utilisation de l'explosif relativement récente. Peut-être s'agit- 
il de la première phase de réexploitation du site dans les années 1960? L'examen plus précis des vestiges aujourd'hui visibles livre quelques indications sur le déroulement de l'exploitation lors des phases antérieures à la reprise industrielle. En effet, les ouvrages anciens préservés donnent une idée des techniques utilisées pour l'extraction du minerai et de la façon d'aborder le gisement qui, semble-t-il à cet endroit, se présentait sous une forme filonienne. Il s'agit avant tout de deux galeries foncées dans la partie basse du parement sud de la carrière, dans sa partie centrale (Fig. 4a et 5). D'un profil ovoïde (dimensions moyennes: $0,8 \times 1,3 \mathrm{~m}$ ), ces galeries horizontales et étagées donnent accès à deux niveaux d'un chantier sub-vertical situé à $8 \mathrm{~m}$ du jour (Fig. 5 et 6). Relativement étroit, ce chantier suivait au plus près la structure minéralisée dont le produit a pu être acheminé, par les galeries, vers un autre secteur de l'exploitation aujourd'hui en grande partie détruit par la carrière. En effet, la multitude d'encoches qui jalonnent la paroi rocheuse au débouché des galeries (Fig. 4a), montre bien que ce chantier était auparavant sub-vertical et relativement étroit, ressemblant probablement au précédent. Les encoches servaient à ancrer des boisages (destinés à maintenir les parois du chantier) au toit et au mur du filon. Les travaux modernes ont détruit une de ses parois, au toit, du côté nord. Moins bien conservée, la partie nord de la carrière des Anciens conserve tout de même en certains endroits des lambeaux de parois anciennes parsemés d'encoches, montrant que ce type d'exploitation couvrait l'ensemble de l'emprise des travaux modernes. À la place de cette grande carrière à ciel ouvert, il faut par conséquent restituer une succession de travaux souterrains, sub-verticaux et étroits, qui suivaient les minéralisations, ainsi qu'on peut l'observer dans d'autres secteurs mieux préservés. À l'extrémité ouest de la carrière, un puits que nous n'avons pu explorer montre que les travaux anciens atteignaient une profondeur importante dans le secteur (au moins une cinquantaine de mètres depuis la surface).

À une cinquantaine de mètres au nord de la partie centrale de la carrière des Anciens, s'ouvre une succession de 5 puits, d'une profondeur moyenne de 5 à $6 \mathrm{~m}$, que les mineurs actuels attribuent à un système traditionnel de collecte d'eau: les khettara ou galeries drainantes (Fig. 7 et 8; García Pulido \& Caballero Cobos 2015). El Ajlaoui (1994: 26) avait observé ces puits et les avait interprétés comme un système de galerie destiné à l'évacuation des eaux de la carrière en direction de l'oued Akka situé (alors) à une centaine de mètres en direction du nord (le secteur est aujourd'hui nivelé). Une exploration très rapide a permis de faire quelques observations et de dresser une topographie schématique de ces aménagements. À leur base, qu'une couche de remblais ne permet pas d'observer précisément, ces puits sont 
reliés entre eux par une galerie horizontale, globalement orientée N-S. Le profil de la galerie est relativement irrégulier mais la partie inférieure est en général plus étroite $(0,75 \mathrm{~m})$ que la partie haute $(1,15 \mathrm{~m})$, qui se termine par un plafond arrondi. Sa hauteur actuelle varie entre 0,6 et 1,5 m, mais partout la sole (qu'El Ajlaoui décrit comme dallée) est recouverte d'une épaisse couche de boue que nous n'avons pu mesurer. Cet ensemble d'ouvrages fait en effet penser à un système d'exhaure qui serait liée à la carrière des Anciens, conçu sur le modèle des khettara. Les puits (tanoute) servent habituellement à l'aération et à la maintenance du réseau. L'aménagement d'une importante piste de circulation pour les engins de la mine actuelle a probablement interrompu la liaison entre la galerie et la carrière.

Le filon Sud 1 livre également des travaux d'extraction anciens. Ils s'étendent sur plus de $50 \mathrm{~m}$ d'est en ouest et sur 4 à $5 \mathrm{~m}$ de largeur (Fig. 9, 10 et 11). Encore visible en plusieurs points, le filon exploité avait une puissance moyenne de $0,5 \mathrm{~m}$, une direction E-W et un pendage quasi-vertical. Le chantier d'exploitation prend ici la forme d'une succession de puits, ou fosses d'extraction, séparés par des piliers, avec une relative régularité, tous les 2 à $3 \mathrm{~m}$. Pour des raisons de sécurité, ces puits ont été partiellement remblayés par l'exploitant actuel, qui n'a eu qu'à déplacer de quelques mètres les anciens cavaliers qui bordaient les travaux. Aujourd'hui, la profondeur des puits ou fosses est comprise entre 2 et $7 \mathrm{~m}$ mais, d'après les informations recueillies, ils étaient auparavant « très profonds ». Pour faciliter la circulation sur un niveau, dans l'axe du chantier, des galeries de petite section ont été foncées dans les piliers. Le puits oblique, excentré par rapport à la minéralisation, devait permettre d'accéder directement depuis le jour aux niveaux inférieurs. Des marches, grossièrement aménagées et espacées de 1 à 1,5 m, sécurisaient la descente. C'est probablement la fragilité de l'encaissant, les pélites, qui explique la morphologie bien particulière de ce chantier. En effet, l'instabilité des parois a contraint les anciens mineurs à laisser de très nombreux piliers, malgré le minerai qu'ils contenaient. Cette technique semble être appliquée surtout dans la partie supérieure des travaux, peut-être en raison de l'absence de confinement des parements et de l'érosion superficielle qui a davantage fragilisé les roches à cet endroit.

Située à l'extrémité est du filon Sud, la carrière B8 est un ouvrage récent destiné à l'exploitation à ciel ouvert. L'excavation, effectuée à la fin du XXe siècle, a entièrement bouleversé le paysage et la topographie locale, recoupant par là-même d'importants chantiers verticaux anciens qui, pour des raisons de sécurité, ont conduit à l'arrêt des travaux. D'ouest en est, plusieurs vestiges miniers sont visibles. Sur la paroi Est de la carrière, dans la partie supérieure, on observe un étroit chantier vertical remblayé (Fig. 12). On ne trouve pas sa trace 
en surface, soit que les travaux ne percent pas au jour, soit que les ouvrages ont été comblés depuis longtemps, entraînant une confusion entre encaissant et remplissage; ce chantier ancien devait probablement se poursuivre en souterrain. Dans la partie centrale, à un niveau intermédiaire, un effondrement a mis au jour une vaste salle d'exploitation, grossièrement circulaire, d'une quinzaine de mètres de diamètre et d'une dizaine de mètres de hauteur. Les travaux anciens se poursuivent en chantier vertical plus étroit, dans l'axe du filon, vers l'ouest comme vers l'est. À une vingtaine de mètres de là, vers le nord-ouest, un petit puits d'aspect ancien a été foncé. À sa base, remblayée, une galerie de section ovoïde, aujourd'hui comblée, prend la direction des travaux précédents. Ce secteur n'a pas été exploré en raison des problèmes de sécurité. Pour les mêmes raisons, le secteur ouest, dans le fond de la carrière, n'a pu être exploré. Les travaux récents se sont arrêtés là sur un chantier vertical relativement profond (plus de $30 \mathrm{~m}$ ) que l'on peut suivre sur une vingtaine de mètres en extension. Les éboulements occasionnés par la carrière compromettent fortement la stabilité du secteur et son accès dans des conditions de sécurité satisfaisantes.

Enfin, une série de puits (appelés « Petits puits » ci-après) a été observée à quelque $350 \mathrm{~m}$ au sud de la carrière des Anciens. Sept puits ont été creusés sur une structure minéralisée sub-verticale (Fig. 13 et 14). Aujourd'hui remblayés, leur profondeur varie de moins de $1 \mathrm{~m}$ à plus de $4 \mathrm{~m}$. Cinq autres puits ou grattages de moindre profondeur sont visibles en périphérie du filon. Vers l'est, une vaste dépression semble indiquer que l'exploitation se poursuivait à ciel ouvert (Fig. 15), mais on ne peut dire si les deux techniques d'extraction appartiennent à la même phase chronologique. Par leur morphologie, ces « Petits puits » rappellent les travaux qui ont été relevés sur le filon Sud 1. Les anciens mineurs semblent en effet avoir utilisé une même technique d'extraction. La seule différence significative est le changement d'échelle entre les deux secteurs d'exploitation, les « Petits puits » étant beaucoup plus étroits et les piliers plus importants. Sans indice chronologique, il est difficile d'interpréter cette variation, qui peut être liée à deux phases successives d'exploitation ancienne ou bien à une simple adaptation des techniques à un contexte local particulier (nature de l'encaissant, de la structure minéralisée, etc.).

L’inventaire des ouvrages miniers conservés en surface à Imiter permet de se faire une première idée de l'exploitation ancienne et de la stratégie adoptée par les mineurs. Les deux filons principaux (nord et sud) ont été attaqués par le haut, depuis la surface, par une série de puits alignés, séparés par d'imposants piliers qui maintiennent les parois fragiles de l'encaissant. Pour des raisons de sécurité, ces travaux ont été comblés depuis, mais une 
première reconnaissance souterraine, par les galeries de l'exploitation actuelle, montre qu'ils atteignent une profondeur comprise entre -50 et $-70 \mathrm{~m}$. Cette puissance d'extraction qui n'excède pas les $80 \mathrm{~m}$ montre que les anciens travaux miniers sont tous situés dans la partie sommitale du gisement, c'est-à-dire dans le chapeau de fer. Pour l'instant, aucun élément chronologique probant ne peut être mis en relation avec ces travaux. Si leur caractère « préindustriel» ne fait aucun doute, on ne peut cependant les attribuer à une (ou plusieurs) période(s) chronologique(s) précise(s).

\section{Le traitement du minerai}

El Ajlaoui écrit que « le site minier est couvert de meules en granit» (1994: 21-22), qu'il compte par centaines, certaines polies par l'usage, d'autres à peine ébauchées. Il a également repéré une laverie constituée d'une centaine de cuves rangées par deux dans une vallée versante orientée au nord (El Ajlaoui 1994: 23-24). Nous n'avons pas la certitude d'avoir localisé cette dernière, mais nous avons pu repérer plusieurs aires de traitement du minerai sur le site. Elles sont situées à proximité des zones d'extraction, aux abords sud-est de la carrière des Anciens, aux abords ouest du filon Sud 1 et aux abords nord de la carrière B8.

Tout d'abord, de très nombreux fragments de meules ont été repérés dans les secteurs de traitement et de transformation du minerai (Fig. 16 et 17). Les plus grosses et les mieux conservées sont prélevées régulièrement par les employés de la mine et gardées au Service Géologique de la compagnie. Un secteur (Point 1 sur la Fig. 3) a livré de nombreux fragments de meules taillées dans différents matériaux, dont principalement la granodiorite (Fig. 18). La diversité des roches utilisées n'est certainement pas due à l'accessibilité des matériaux mais aux différents travaux réalisés par les métallurgistes. En effet, chacune présente une dureté différente. Un fragment (Fig. 19a) a particulièrement attiré notre attention, car le même faciès se retrouve dans un spécimen de meule trouvé dans le secteur A de la fouille de Sijilmâsa en 2014 (Fig. 19b). Il s'agit d'une roche peu commune: la phonolite. C'est une roche magmatique volcanique microlithique de couleur grise à verdâtre. Elle se présente sous forme d'une pâte de verre dans laquelle baignent des phénocristaux très abondants composés essentiellement de feldspaths alcalins de la série anorthose-sanidine et de feldspathoïdes représentés par la néphéline qui se présente généralement en tablettes automorphes millimétriques.

Au cours de nos prospections autour de la concession d'Imiter, nous avons nousmêmes repéré, à $250 \mathrm{~m}$ au sud du Point 7 (Fig. 3), un affleurement de phonolite. 
L'affleurement montre l'intrusion d'un dyke qui recoupe les schistes encaissants. Les schistes ont subi un métamorphisme de contact, ce qui donne une roche avec des minéraux ovoïdes noirs et très durs. Ce filon a une puissance d'environ $100 \mathrm{~m}$ et une orientation N60-90/40S (Fig. 20). Sur le plan géologique, il existe d'autres contextes phonolithiques dans l'Anti-Atlas: dans le Jbel Saghro (le massif où se trouve le gisement argentifère d'Imiter) et dans le Jbel Siroua (à 200 km au sud-ouest de Ouarzazate; Berrahma \& Delaloye 1989; Berrahma et al. 1993; Ibhi et al. 2002). La proximité géographique plaide en faveur du Saghro comme lieu d'origine de la meule de Sijilmâsa, qui semble aussi beaucoup plus proche des phonolites du sud-est du point de vue morphologique. Afin de trancher la question d'un potentiel lien génétique (et donc d'une circulation de cette matière première) entre la région du Saghro ou du Siroua et Sijilmâsa, il faudra entreprendre une étude pétro-géochimique. Il restera aussi à reprendre l'étude des cartes géologiques de la région et éventuellement un travail sur le terrain pour s'assurer de l'absence de ces formations dans les zones limitrophes de la ville de Sijilmâsa, en particulier la boutonnière de l'Ougnat. À noter, en complément, que les meules présentes sur le site de Zgounder sont préférentiellement en phonolithe (El Ajlaoui 2008: 51).

Dans un rayon de 30 mètres autour du Point 9 (Fig. 3) et au contact d'une zone de remblai qui livre une abondance relative de céramique et un peu de scories, on observe de très nombreux éléments d'outillage lithique de broyage et de mouture. Leur nombre est suffisamment important pour permettre, à la faveur d'une collecte et d'une étude in situ, d'y repérer deux types: d'une part, les meules dormantes à surface planes ou erratiques, présentant des cupules polies circulaires régulières de 5 à $6 \mathrm{~cm}$ de diamètre (Fig. 21a); d'autre part, les meules dormantes à surface plano-concave, fortement polie mais sans trace d'abrasion visibles à l'œil nu. Plusieurs exemplaires, dont un remarquable, présentent une surface du premier type et une surface opposée du second type. Dans tous les cas observés, les cupules n'ont jamais été pratiquées sur la surface plano-concave. Cette typologie, encore sommaire, laisse néanmoins entrevoir deux technologies très différentes: le concassage ou broyage dans le premier cas, la mouture fine par va-et-vient dans le second. Ces deux technologies peuvent être dans un rapport de succession chronologique. Mais on aurait plutôt tendance à les voir dans un rapport de complémentarité fonctionnelle, du fait qu'aucune surface plano-concave n’a été remployée. Parmi les autres outils présents dans le secteur, on observe également des meules rotatives en fragments, avec percement central, et des meules à main pour va-et-vient. Un objet remarquable de petite taille présente trois surfaces avec cupules et une surface ayant 
servi de percuteur (Fig. 21b). Observée à la loupe de géologue, la surface de l'outil présente des petits morceaux d'argent.

Plusieurs secteurs ont livré des cuves. À quelques dizaines de mètres au nord des travaux de la carrière B8, 15 cuves creusées dans le substrat ont été repérées en 2011 de part et d'autre d'un ancien oued. Il s'agit d'un secteur figurant sur la carte d'El Ajlaoui (Fig. 2). Le secteur étant aujourd'hui particulièrement perturbé par des tractopelles, il a à peine pu être reconnu en 2012: 5 cuves avaient disparu, enfouies ou détruites. Les cuves possèdent un diamètre compris entre 0,7 et $1,8 \mathrm{~m}$ et une profondeur de plus de $50 \mathrm{~cm}$. Organisées en batteries, disposées en arc-de-cercle et ordonnées selon leur diamètre, il s'agit sans nul doute de cuves de traitement du minerai dans lesquelles, par gravimétrie, les Anciens procédaient à une succession d'opérations (débourbage, lavage et concentration; Domergue 2008). En 2012, deux de ces cuves ont fait l'objet de sondages et de relevés topographiques (Fig. 22 et 23). La première (Cuve $A)$ possède un diamètre plus petit $(140 \mathrm{~cm})$ que la seconde (Cuve $B)(180$ $\mathrm{cm})$, mais elle est plus profonde $(70 \mathrm{~cm}$, contre $40 \mathrm{~cm}$ pour la seconde). Le remplissage des cuves fouillées comporte à la base une fine couche noire constituée de cendre et de charbons de bois. Celle-ci est surmontée par une épaisse couche de sédiment pélitique fin brunâtre à gris foncé. Le comblement se termine par une couche de $15 \mathrm{~cm}$, hétérogène et non compacte, de sédiments marrons constitués de limon et de divers détritus centimétriques. Un charbon de bois a été prélevé dans la fine couche noire à la base du remplissage de la cuve B. Sa datation place le remplissage de la cuve durant les Ve-VIe siècles cal $\mathrm{AD}^{5}$. Nous ne pouvons pas déterminer si le remplissage est contemporain de la dernière utilisation de la cuve ou s'il est postérieur à l'abandon de celle-ci.

Dans un autre secteur, cette fois à l'extrémité ouest du filon Sud 1, à proximité immédiate du dernier puits de mine, sept cuves de traitement ont été repérées. Creusées dans le substrat, elles ont un diamètre compris entre 1,1 et 1,9 $\mathrm{m}$. Toutes sont en partie remblayées. Toujours à proximité du filon Sud 1, mais cette fois au sud, d'autres cuves sont également présentes. Le Point 8 (Fig. 3) présente un alignement N-S de 4 cuves. Elles sont décaissées dans le schiste, ce qui donne une allure très faillée et friable aux parois des structures. Une autre est présente, à $10 \mathrm{~m}$ à l'est du précédent groupe. Nous sommes là en bordure sud d'une tranchée ancienne, orientée E-W et longue d'une soixantaine de mètres. Ces structures

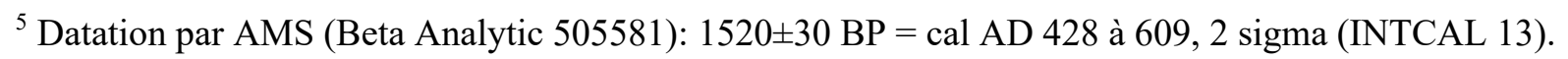


présentent toutes la même apparence: des cuvettes creusées, d'environ $1 \mathrm{~m}$ de diamètre pour ca. $30-40 \mathrm{~cm}$ de profondeur, aux bords très irréguliers.

Au Point 9 (Fig. 3), à $15 \mathrm{~m}$ au nord du Point 8, nous avons observé au sol, en 2014, un arc de cercle d'enduit de chaux affleurant. Dans les conditions imparties par le temps, un sondage rapide fut réalisé. Il mit au jour une fosse de morphologie similaire à celles des cuves repérées en d'autres endroits du site, mais revêtue d'un enduit sur sa paroi interne (Fig. 24). Nous interprétons ce revêtement comme devant permettre l'étanchéité de la cuve de traitement. L'encaissant est un substrat schisteux. La cuve a des parois sub-verticales et un fond concave; sa section horizontale est oblongue. Elle se présentait, avant la fouille, colmatée jusqu'à la surface du sol actuel. Son diamètre maximum était de $1 \mathrm{~m}$ à l'ouverture et sa profondeur de $0,55 \mathrm{~m}$. Une moitié de la structure a été fouillée afin de pouvoir observer le remplissage en coupe (Fig. 25). De bas en haut, le remplissage était constitué de: $10 \mathrm{~cm}$ de limon (dépôt naturel de décantation) emballant de nombreux blocs de schiste érodés et quelques charbons, qui ont été datés (voir plus bas); $15 \mathrm{~cm}$ de sédiment pulvérulent gris (cendreux) associé à une fraction limoneuse emballant des fragments de céramiques, le tout reposant sur un niveau de charbon (on ne peut exclure ici la réutilisation de cette structure en creux comme foyer); enfin, en partie supérieure, $30 \mathrm{~cm}$ de remplissage limono-sableux emballant une grosse fraction constituée de blocs de schistes, le litage apparent indiquant des apports successifs de sédiments, vraisemblablement par ruissellement. Ce remplissage naturel (n'excluant pas la présence de mobilier anthropique) est postérieur à la dernière utilisation de la structure comme cuve de traitement. Deux prélèvements de charbon ont été effectués au fond de la structure, l'un au contact du revêtement (Beta 390996), l'autre dans la partie basse du remplissage (Beta 414103). Les analyses ont livré des datations entre le IIe siècle cal BC et le Ier siècle cal $\mathrm{AD}^{6}$. Compte tenu du fait que les deux échantillons ont livré des résultats radiométriques strictement identiques, on ne peut exclure qu'ils proviennent du même élément organique initial. Quoi qu'il en soit, ces datations datent l'événement du dépôt postérieur à la dernière utilisation du fond de la cuve à ciel ouvert.

La fouille du remplissage de la cuve $\mathrm{C}$ effectuée, des observations ont été pratiquées au sujet de l'aménagement de la structure. L'intérieur de la cuve étant intacte, un microsondage réalisé en fin de fouille dans l'épaisseur du revêtement latéral a montré que la paroi brute, décaissée et présentant de grosses irrégularités et aspérités, a été parée de petits blocs de

\footnotetext{
${ }^{6}$ Datation par AMS (Beta Analytic 390996): 2040 \pm 30 BP = cal BC 155 à AD 25, 2 sigma (INTCAL 13). Datation par AMS (Beta Analytic 414103): identique.
} 
schiste. Ces petits blocs étaient posés à plat et non dans l'orientation des schistosités naturelles de l'encaissant. Sur ce parement a ensuite été nappé un chemisage en argile rouge de 2-3 cm d'épaisseur, qu'est venu à son tour revêtir un enduit de chaux d'1 cm d'épaisseur (Fig. 24). La fouille de cette cuve a répondu à une interrogation omniprésente durant les prospections: comment expliquer le caractère en apparence très rudimentaire de ces cuves simplement creusées dans le schiste et n'offrant pas de garantie d'étanchéité, alors que leur usage comme cuve de traitement du minerai implique la présence d'eau? Nous avions, en cours de mission, recouru à l'hypothèse de fonçages de bois ou de revêtements de peaux pour expliquer le fonctionnement de telles structures. En révélant une structure dont le revêtement interne est conservé et tout à fait compatible avec la fonction de préparation du minerai, la cuve $\mathrm{C}$ permet de penser que les autres cuves ne doivent leur apparence plus fruste qu'à la disparition de leur revêtement intérieur.

Au Point 2 (Fig. 3), nous avons observé deux structures maçonnées, de forme quadrangulaire, en contrebas l'une de l'autre (Fig. 26). Une ravine les traverse d'est en ouest dans le sens de la pente. Un rapide nettoyage de ces structures nous a indiqué que les parties latérales n'étaient pas à proprement parler des murs mais des parements aménagés contre des parois décaissées dans le substrat. Ceci plaide pour une faible élévation, donc davantage en faveur de bassins que d'habitats. Un reste d'enduit plaqué sur un parement intérieur d'une des deux structures renforce du reste cette hypothèse. Quoique la situation topographique de ces bassins soit en haut d'un thalweg, en rebord supérieur du bassin versant, ils ont pu jouer le rôle de collecteurs des eaux de ruissellement, ainsi qu'en témoigne la ravine actuelle, non contrôlée, qui a tronqué les structures anciennes en les mettant au jour. Mais on peut aussi bien envisager un autre moyen (manuel ou par adduction) de remplissage de ces structures. Qu'ils soient liés à une fonction d'adduction paraît être confirmé par la présence d'une cuve (une seule cuve observée) de traitement du minerai à une dizaine de mètres en direction de l'ouest, en contrebas. Ces bassins pourraient avoir servi de réservoirs assurant l'adduction d'eau en direction des cuves. Nous ne pouvons émettre aucune hypothèse assurée quant aux modalités de remplissage de ces bassins, ni sur les systèmes d'adduction entre les réservoirs et les cuves.

Il n'est pas évident d'établir le fonctionnement des structures (cuves de traitement et réservoirs) observés à Imiter et de comprendre l'organisation de ces zones de traitement du minerai, faute d'en avoir une vision d'ensemble. De plus, nous ne disposons que de très peu d'exemples archéologiques permettant d'émettre des comparaisons et interprétations. Nous ne 
connaissons pas d'exemples islamiques où de telles structures sont à la fois décrites et datées. En Europe, à la période médiévale, les structures liées à la minéralurgie sont en bois, à l'instar de celles, très bien conservées, du site de Jihlava en République tchèque (Hrubý 2011). C'est le site antique de Carthagène, dans le sud de l'Espagne, qui nous fournit les meilleurs éléments de comparaison (Rico et al. 2009; Antolinos Marín \& Rico 2012), confortés par les datations antiques que nous avons obtenues à Imiter. Carthagène est un exemple rare, qui n'a pour l'instant pas d'équivalent pour la période antique: les laveries du Laurion, par exemple, ne reproduisent ni le plan ni l'organisation de l'atelier de Carthagène. À Carthagène, a été étudié un ensemble d'installations minéralurgiques datant de la fin de l'époque républicaine (IIe-Ier siècle avant notre ère). Plusieurs cuves possédant un même mode de construction ont été fouillées. Contrairement à celles d'Imiter qui sont creusées dans le substrat, elles sont aménagées dans un remblai et leur élévation consiste en un assemblage de blocs de pierres liés à la terre. Cependant, comme à Imiter, les parois intérieures sont revêtues d'un enduit permettant leur étanchéité. À Carthagène, les cuves présentent plusieurs formes: les cuves à double réservoir permettant un premier lavage du minerai préalablement broyé, les cuves simples permettant de concentrer le produit issu du premier lavage. Dans ces dernières remplies d'eau, les Anciens mettaient le minerai débourbé et remuaient le mélange de manière à favoriser la décantation. Les cuves d'Imiter sont assez proches de ces dernières par leur morphologie, dimensions et absence de double réservoir. Toutefois, elles ne présentent pas de canalisation dans la partie supérieure permettant l'évacuation du trop-plein comme c'est le cas à Carthagène. Il est cependant possible que nous n'ayons mis au jour à Imiter que des cuves arasées en partie supérieure. Quoi qu'il en soit, la comparaison technologique et morphologique avec Carthagène nous autorise à penser que les cuves d'Imiter ont été utilisées pour la décantation dans la phase d'enrichissement du minerai. Cette hypothèse laisse cependant intacte la question impérieuse de l'approvisionnement et de la gestion de l'eau lors du traitement du minerai avant les opérations métallurgiques. Relevons cependant qu'Imiter, comme Carthagène, a livré une structure rectangulaire de type bassin à proximité des cuves. À Imiter, nous avons proposé d'y voir un bassin d'alimentation des cuves, alors que la structure similaire de Carthagène est interprétée comme ayant recueilli l'eau s'écoulant des cuves de décantation. Le système d'adduction d'Imiter ne pourrait être éclairci que par des fouilles extensives entre la zone des cuves et celle des bassins, si toutefois les structures de surface ont été conservées. 


\section{La transformation du minerai en métal}

El Ajlaoui avait signalé la présence sur le site d'Imiter de très abondantes scories, concentrées dans et aux alentours de ce qu'il désigne comme l'ensemble principal d'habitat (Fig. 2; El Ajlaoui 1994: 15, 21-23), qui n'est pas conservé ou que nous n'avons pas retrouvé en l'état. Il indiquait également avoir localisé une zone, distincte de la précédente, livrant une forte présence de creusets (rencontrés «par centaines »), située entre la Borne 3 et la Borne 8 (Fig. 3). Cette dernière zone, que nous n'avons pas non plus retrouvée, avait livré des restes de fours ainsi que des vestiges d'os brûlés. Ces derniers ont permis à El Ajlaoui d'émettre l'hypothèse selon laquelle de la poudre d'os (phosphate et calcium) entrait dans la composition du matériau argilo-organique avec lequel étaient produits les creusets. L'un de ces creusets (Fig. 27), soumis par El Ajlaoui à une analyse élémentaire par fluorescence X (El Ajloui 2008: 53), avait révélé, sur la surface alvéolée, la présence de fer et de plomb. Ces deux éléments chimiques sont souvent présents dans les minerais d'argent des parties sommitales des minéralisations (comme pour d'autres types de minerais). Pour El Ajlaoui, ces résultats prouvaient que les creusets avaient été utilisés par les fondeurs pour couler des préformes monétaires. Il faut cependant rester prudent. En effet, l'article ne présente pas le protocole analytique, ni les modalités de mise en œuvre de la méthode employée pour ce type de surface hétérogène, ni les données brutes. Par ailleurs, l'absence de démonstration de la reproductibilité des mesures sur l'objet en question et de la représentativité de ces dernières, ne permettent pas une interprétation poussée.

Le secteur que nous avons, quant à nous, identifié comme zone de transformation métallurgique peut, ou pas, être un vestige de la zone des scories d'El Ajlaoui, considérablement remaniée et rognée par les travaux de surface des dernières décennies. Située à proximité immédiate de la carrière des Anciens, au sud-ouest de cette dernière, sur un glacis légèrement pentu encerclé par des terrils modernes, une vaste zone de traitement minéralurgique et de transformation métallurgique a été identifiée grâce à la présence d'abondants fragments de meules, de scories et de parois de four vitrifiées, ainsi que de plus rares tessons (Fig. 28). Centrée sur le Point 1 (Fig. 3), elle est désignée comme « Site à scories » dans la suite de cet article. Les alentours de cette zone témoignent d'une remobilisation importante des sols (arrachements de socle rocheux par les tractopelles), mais le « Site à scories » à proprement parler, quoique partiellement tronqué par les engins mécaniques, paraît relativement préservé. La zone semble préserver en tout cas un potentiel archéologique sur environ un hectare. Un large épandage de scories et de parois de fours en 
bas de pente suppose une démolition provenant du haut de ce léger relief. Ces indices semblent traduire une activité de réduction de minerai. Néanmoins, aucune structure en élévation n'est aujourd'hui visible. Les échantillons céramiques présents sont de gros fragments de poteries très disparates: formes larges à pâte rouge et fine, tessons à glaçure verte, pâte à engobe blanc ou rouge. Les décors sont rares. Compte tenu de la transformation importante du paysage et de l'occultation des surfaces par les déblais modernes, nous avons réalisé deux très rapides sondages de faible emprise $(40 \times 40 \mathrm{~cm})$ afin de vérifier l'intégrité et le potentiel du sous-sol. L'un a été réalisé sur le promontoire à l'ouest du secteur, où ne se rencontrent en surface que des meules, à l'exclusion de tout autre artefact. Le sondage a livré un sédiment brun limono-sableux. Un sol apparaît à $50 \mathrm{~cm}$ sous la surface, comportant un fragment de meule surmontant une couche de cendres. Le socle rocheux n'a pas été atteint. L'autre sondage a été pratiqué dans un secteur en surface très cendreux. Il a livré un sédiment cendreux et pulvérulent. Un sol brûlé apparaît à $50 \mathrm{~cm}$ sous la surface. Le socle rocheux n'a pas été atteint non plus.

\section{Discussion: récapitulation et limites des données archéologiques}

D’un point de vue archéologique, nos courtes missions à Imiter ont permis de documenter tous les segments de la chaîne opératoire de la transformation du minerai argentifère en métal. Les imposants restes de la « carrière des Anciens » et de plusieurs autres carrières anciennes permettent de documenter la phase d'extraction du minerai. L'identification en prospection de batteries de cuves de traitement et la fouille de trois d'entre elles, le repérage de bassins possiblement liés à l'alimentation en eau des batteries de cuve, constituent des résultats importants. Enfin, le site a livré des vestiges de transformation du métal: des observations de surface permettent en effet d'envisager avec un certain degré de confiance la présence de bases de fours de réduction. En revanche, aucun indice de coupellation n'a à ce jour été découvert, si elle a été pratiquée sur le site minier. Enfin, des creusets pour la coulée de billes d'argent ont été décrits avant nous; un semblable abaque ou moule à billes est conservé dans la salle de réunion de la direction de la mine. Signalons enfin que, à la différence d'El Ajlaoui, nous n'avons trouvé de fragments de creuset lors d'aucune de nos trois courtes missions, dans aucun secteur de la mine d'Imiter. De même, nous n'avons pas trouvé de fragments de verre, dont El Ajlaoui (1994: 15) dit que le site est couvert. 
En termes de datation, les travaux conduits jusqu'à présent à Imiter attribuaient l'exploitation de la mine à la période islamique. Les résultats des trois datations obtenues par nous dans deux cuves placent leur utilisation avant la période islamique, et même, pour deux d'entre elles, au tournant de notre ère, soit six à huit siècles avant l'évènement de l'Islam au Maroc. Nous livrons ces résultats avec prudence, car pour l'instant il n'existe pas d'autres données indiquant l'existence d'une métallurgie durant la période antique au sud du limes romain. Ajoutons que les vestiges archéologiques observés à Imiter sont, pour la plupart, non datés, et que rien n'indique qu'ils soient contemporains les uns des autres. Ils ont pu intervenir dans la chaîne opératoire au cours de plusieurs phases d'exploitation du site, de l'antiquité à l'époque moderne. Pour l'heure, nous considérons que l'identification proposée par El Ajlaoui (1994) entre le site d'Imiter et l'ancienne Todgha reste probante.

Cette identification entre Imiter et Todgha est basée sur l'examen des sources écrites qui mentionnent l'exploitation de l'argent à Todgha et situent cette localité dans l'orbite géographique de Sijilmâsa, cité qui prend son essor à ses dépens au VIIIe siècle de notre ère. El Ajlaoui (1994: 29) évoque également la découverte sur le site d'Imiter de trois pièces de monnaie (deux dirhams idrissides et un fals en cuivre) datées du VIIIe siècle, précisément à la fin de la période d'indépendance de Todgha. Ajoutons un argument en faveur du lien entre les deux villes: la présence sur les deux sites, signalée plus haut, de meules fabriquées dans un matériau rare, la phonolithe. Enfin, l'oued qui coule à Tinghir, la grosse localité actuelle voisine d'Imiter, porte précisément le nom de Todgha, ce qui invite à penser que la cité ancienne portait le nom de l'oued (ou inversement), comme c'est fréquemment le cas en onomastique marocaine. Tout ceci renforce l'identification faite par El Ajlaoui.

Nous avons cependant été incapables de retrouver les ruines décrites par El Ajlaoui (1994: 20). Celui-ci évoque une « concentration remarquable [de ruines] dans la zone ouest d'Imidar (i.e. Imiter), où elles couvrent une superficie de 60 hectares » s'étirant, en direction du sud-ouest, à partir des abords immédiats de la carrière A (carrière des Anciens; Fig. 2). Il y distingue plusieurs ensembles, notamment un ensemble principal, fortifié, regroupant des maisons importantes, et d'autres ensembles plus modestes, situés de part et d'autre de l'oued Tighouziouine, qu'il apparente à des habitats de mineurs, décrits ainsi: « Les ruines [...] ont une forme circulaire de $10 \mathrm{~m}$ de diamètre. Elles constituaient un habitat fortifié ». Ces vestiges ne sont malheureusement pas plus précisément décrits ni n'ont été photographiés par l'auteur; il est donc difficile de s'en faire une idée précise. 
Ces ruines étaient-elles celles de Todgha au sens propre ou bien celle d'un habitat d'artisans et de mineurs exploitant le site pour le compte d'une élite urbaine résidant à quelque distance? En l'absence d'une reconnaissance des vestiges vus par El Ajlaoui, il est difficile de se prononcer sur le statut social des habitants. El Ajlaoui évoque la présence, dans la même zone d'habitat, d'une « céramique glaçurée, traduisant [...] une vie aisée de la population » (1994: 15). Nous ne pouvons pas nous prononcer, force étant de constater que la zone d'habitat vue par El Ajlaoui était située, partiellement ou en totalité, à l'emplacement actuel (2011-2014) d'immenses haldes modernes et de secteurs arasés par les engins de chantier. Jusqu'à quel point les vestiges d'habitat sont détruits ou simplement masqués est une question que nous ne pouvons résoudre. Enfin, il est également possible que nos observations, limitées dans le temps, aient manqué en partie leur cible: nous n'avons en effet pas prospecté certains secteurs, notamment au nord de l'oued Akka.

Pour défendre ici une vision optimiste, suggérons que les ruines vues par El Ajlaoui et aujourd'hui détruites ou occultées étaient celles de la cité minière, pas nécessairement celles de la ville de Todgha. Les environs de la concession minière, que nous avons prospectés de façon non systématique, n'ont certes pas livré de vestiges significatifs. Mais rien n'interdit d'émettre l'hypothèse que le pôle urbain médiéval se trouverait encore dans une zone non prospectée aux abords de la concession, ou dans un périmètre plus éloigné. Nous suggérons que la cité, antérieure au XIe siècle (al-Bakrî en parle au passé), serait à rechercher dans la vallée du fleuve Todgha. L'association entre la cité (de Todgha) elle-même et le centre industriel (Imiter sous son nom actuel) fut peut-être davantage le fait d'un rapport de contrôle politique et économique que celui d'une proximité géographique.

\section{Géologie et géochimie du minerai d'Imiter, et hypothèses sur les minéralisations recherchées par les Anciens}

Le district minier d'Imiter se situe dans une vaste boutonnière minéralisée où de l'argent natif, entre autres, se déploie à grande échelle. La mise en place de cette minéralisation argentifère s'est déroulée en deux épisodes: un épisode mineur, hydrothermal, qui a permis la mise en place de différents types de minéralisations comme des pyrites, arsénopyrites, galènes et cuivre gris; un épisode majeur, épithermal, qui se caractérise par une minéralisation où domine l'argent natif. Ce dernier épisode se divise à son tour en deux phases: une phase riche en quartz et une autre en dolomite. Le district minier d'Imiter, peu étendu géographiquement, 
possède ainsi quatre grands types de minéralisations. Elles sont toutes riches en argent et se présentent sous différentes formes: des amalgames d'argent $(\mathrm{Ag})$ et de mercure $(\mathrm{Hg})(\mathrm{avec}$ localement jusqu'à 40\% de Hg en masse), de l'argent natif (sous forme de cheveux d'ange), des sulfures d'argent, notamment de l'imitérite (Guillou et al. 1985), et des minerais sulfureux à base d'arsenic, plomb (galènes argentifères), zinc, cobalt et nickel (Levresse et al. 2018).

D'après les géologues de la mine, les Anciens ont dû avoir accès, dans un premier temps, à la première forme de minéralisation: des plaques d'argent natif amalgamé avec du mercure. Aucune preuve d'exploitation de cette minéralisation ne semble visible sur le terrain. Cependant, à en juger par la forte densité de scories anciennes et de parois de four, actuellement répandues sur une aire géographique relativement bien délimitées au sein du district (Fig. 3), les Anciens n'ont pas exploité uniquement l'argent natif (si tel est bien le cas) mais bien plusieurs autres types de minéralisations. Pour répondre à cette hypothèse, des prélèvements de minerais, de parois de four et de scories pour analyses minéralogiques et géochimiques ont été effectués afin d'identifier les matières premières exploitées et le traitement métallurgique opéré et d'attribuer une signature isotopique à cette ancienne production (Milot et al. 2018).

Les observations microscopiques ont mis en lumière la coexistence de différents types de billes de métal dans les scories. Des billes (i) de plomb pur; (ii) de plomb/argent; (iii) de plomb-cuivre. Ces observations suggèrent que le(s) minerai(s) exploité(s) à Imiter par les Anciens avaient une nature polymétallique (des galènes argentifères par la présence du plomb, des sulfures pouvant expliquer la présence du plomb et du cuivre ainsi que d'autres minéraux). Cela est en adéquation avec les différents types de minéralisations mis en lumière par les études géologiques antérieures. La matrice silicatée des scories est par ailleurs très riche en fer et en plomb. Le plomb a pour origine la galène (notamment sulfure de plomb argentifère) et sa présence, à la fois dans les billes et dans la matrice silicatée, s'explique par le fait que les Anciens, pour des raisons techniques propres à leur époque, ne pouvaient pas extraire entièrement le plomb des minerais traités (et donc de l'argent, puisque les deux métaux sont associés chimiquement). La présence de fer dans la matrice des scories confirme, quant à elle, le constat des géologues sur la présence de chapeaux de fer dans la partie sommitale/superficielle des veines minéralisées riches en argent d'Imiter (Cheilletz et al. 2002). La plupart des scories issues de la métallurgie des non ferreux contiennent du fer dans la matrice silicatée, selon des proportions très variables. Ce fer peut avoir deux origines possibles: la minéralisation elle-même ou des ajouts, opérés durant le procédé métallurgique. 
Si le fer est un ajout, cela se traduit par des billes de fer métallique dans la matrice silicatée des scories. Aucune bille de fer n'a été observée dans les matrices silicatée des scories d'Imiter. Ainsi, le fer présent proviendrait plutôt du ou des minerais exploités et réduits par les Anciens, minerais situés dans la partie sommitale des gisements où sont encore visibles les vestiges anciens d'exploitation minière (Milot et al. 2018).

L'étude minéralogique de ces scories semble donc attester que l'exploitation ancienne s'est focalisée sur (un ou plusieurs) minerais polymétalliques (par la présence, entre autres, de fer, de cuivre et de plomb) riches en argent (différents types de sulfures).

Nous avons voulu également caractériser les signatures isotopiques de cette production ancienne en vue de futures études de provenance. Pour ce faire, les compositions isotopiques du plomb et du fer ont été mesurées sur ces mêmes échantillons par l'utilisation d'un spectromètre de masse de haute résolution. Un nouveau traceur, les isotopes du fer, a été testé ici, pour deux raisons principales. Tout d'abord, la littérature sur les données en isotopie du plomb à Imiter indique que le gisement possède une très grande hétérogénéité, liée aux conditions génétiques des minéralisations (Pasava 1994; Levresse et al. 2018). Ensuite, bien que la mesure des compositions isotopiques du plomb sur des déchets métallurgiques réduise l'hétérogénéité des minerais (Baron et al. 2014), un nouveau traceur est toujours le bienvenu car la signature d'un gisement, qu'elle soit hétérogène ou non, n'est jamais unique. Inversement, différents gisements, géographiquement éloignés ou non, peuvent présenter des signatures isotopiques identiques. Toutes ces raisons constituent une limite majeure dans la résolution d'une étude de provenance. Les résultats des analyses isotopiques du plomb qui ont été menées sur les scories, parois de fours et galènes révèlent des compositions similaires aux signatures des galènes du district d'Imiter (Pasava 1994). Cela se traduit par deux groupes de compositions isotopiques très différentes. Les signatures de chacun de ces deux groupes reflètent les deux sources de fluides à l'origine de la mise en place des minéralisations. Les Anciens ont donc exploité un ou plusieurs type(s) de minerais aux signatures isotopiques très différentes et sans relation génétique (Essarraj et al. 2016; Milot et al. 2018). Cette hétérogénéité des isotopes du plomb, mesurée sur les scories et les parois de four, ne permet pas d'attribuer une signature fine à cette production d'argent. C'est pourquoi des analyses isotopiques du fer sont les bienvenues. Pratiquées sur les scories, elles montrent une signature unique et très homogène, contrairement aux compositions isotopiques du plomb. Considérant que le fer contenu dans les scories est l'héritage des minéralisations, la signature isotopique de tous nos échantillons reflète donc bien celle des minerais exploités par les Anciens à Imiter. 
Les isotopes du fer constituent ainsi un traceur discriminant de la production d'argent, pour le cas du district minier d'Imiter (Milot et al. 2018). Il s'agit là d'une voie prometteuse pour de futures études de provenance en complément des isotopes du plomb. Cette étude démontre l'intérêt du couplage des traceurs pour affiner la signature chimique d'une production métallique dans un contexte géologique donné. L'avenir des études de provenance est aujourd'hui dans le couplage des traceurs. L'isotopie du fer n'a jamais été utilisée en paléométallurgie des non ferreux; il n'est donc pas encore possible de comparer ces nouvelles données à d'autres.

\section{Remerciements}

Toutes les missions sur le site d'Imiter ont été conduites avec l'autorisation de la Société Métallurgique d'Imiter. Nous devons ici saluer le soutien que nous avons reçu de la part des responsables de l'exploitation et des géologues de la mine, qui nous ont donné accès à leur documentation (rapports, cartes, coupes, photographies aériennes) et nous ont souvent guidés vers les vestiges anciens connus d'eux. Nous tenons à remercier la direction de la mine, le Service de Géologie et le Service Traitement, pour leur accueil et leur collaboration efficace durant nos visites sur le site. Nos remerciements nominaux vont à MM. Aziz Gaouzi, Mohamed Mouhajir, Nabil Atlassi, Mohamed Benmoumen, Farid El Hamdaoui et Hicham Rami. Les missions sur le site ont été financièrement rendues possibles grâce à des fonds du laboratoire TRACES (fonds d'amorçage 2011), du Pôle Métal du laboratoire TRACES, de la Maison des Sciences de l'Homme et de la Société de Toulouse (MSHS-T), de l'Idex de 1'Université Fédérale de Toulouse, de la Commission des fouilles du ministère des Affaires étrangères (programme « Sijilmâsa : ville, oasis, carrefour ») et de la Société Métallurgique d'Imiter (Groupe Managem). Nous remercions les deux rapporteurs anonymes sollicités par la revue, ainsi que Nicolas Minvielle (LA3M UMR 7298) et Christian Rico (TRACES UMR 5608) qui nous ont apporté maintes précisions au sujet de Carthagène.

\section{Bibliographie}

Amade, E. 1963. Bilan des travaux effectués sur le champ filonien d'Imiter (Djebel Sarho). BRPM-C1, (431-17. Ga 3, 01).

Antolinos Marín, J.A. \& Rico, C. 2012. El complejo mineralúrgico de época 
tardorrepublicana del Cabezo del Pino (Sierra de Cartagena, Murcia). In: Zarzalejos Prieto, M., Hevia Gómez, P. \& Mansilla Plaza, L. (eds.), Paisajes mineros antiguos en la Penínsola Ibérica: investigaciones recientes y nuevas líneas de trabajo. Universidad nacional de educación a distancia, Madrid, pp. 69-90.

Baron, S., Souhassou, M. \& Fauvelle, F.-X. 2020. Medieval Silver Production around Sijilmâsa, Morocco. Archaeometry 62 (3), 593-611.

Baron, S., Tamas, C.G. \& Le Carlier, C. 2014. How Mineralogy and Geochemistry Can Improve the Significance of Pb Isotopes in Metal Provenance Studies. Archaeometry 56 (4), 665-680.

Berrahma, M. \& Delaloye, M. 1989. New Geochronological Ideas on the Volcanic Massif of Siroua, Anti-Atlas, Morocco. Journal of African Earth Sciences 9 (3-4), 651-656.

Berrahma, M., Delaloye, M., Faure-Muret, A. \& Rachidi, H.E.N. 1993. New

Geochronological Data on Alkaline Volcanism at Jbel Saghro, Anti-Atlas, Morocco. Journal of African Earth Sciences 17 (3), 333-341.

Cheilletz, A., Levresse, G., Gasquet, D., Azizi-Samir, M., Zyadi, R., Archibald, D.A. \& Farrar, E. 2002. The Giant Imiter Silver Deposit: Neoproterozoic Epithermal Mineralization in the Anti-Atlas, Morocco. Mineralium Deposita 37 (8), 772-781.

Colin, G.S. 1936. Les Mines marocaines et les Marocains. Bulletin économique du Maroc 3, 194-200.

Colin, G.S. 1954. L'exploitation de la mine d'argent de Zgouder (Siroua) au XIIIe siècle. Hespéris 41, 229-230.

Couturejuzon Colomez, S. 2014. La mine et la métallurgie au Maroc du premier âge des métaux à la fin du Moyen Age. Unpublished MA Thesis, Université Jean Jaurès, Toulouse. Cressier, P. 2004. Du sud au nord du Sahara: la question de Tāmdult. In: Bazzana, A. \& Bocoum, H. (eds.), Du nord au sud du Sahara. Cinquante ans d'archéologie française en Afrique de l'Ouest et au Maghreb. Bilan et perspectives. Sépia, Paris, pp. 275-284.

Cressier, P., Erbati, E., AcienAlmansa, M., El Boudjay, A., Gonzalez Villaescusa, R. \& Siraj, A. 2001. La naissance de la ville islamique au Maroc (Nakūr, Aġmāt, Tāmdult). Résultats préliminaires de l'approche archéologique du site de Nakūr (capitale d'un émirat du haut Moyen Âge). Actes des Premières journées nationales d'archéologie et du patrimoine 3, 108119.

Devisse, J. 1990. Commerce et routes du trafic en Afrique occidentale. In: El Fasi, M. \& Hrbek, I. (eds.), Histoire Générale de l'Afrique. III. L'Afrique du VIIe au XIe siècle. Unesco, 
Paris, pp. 397-463.

Domergue, C. 2008. Les mines antiques. La production des métaux aux époques grecque et romaine. Picard, Paris.

El Ajlaoui, M. 1994. La mine d'argent d'Imidar et la question de Todgha (VIIIe-Xe siècle): vers une hypothèse. Hespéris Tamuda 32 (1), 11-34.

El Ajlaoui, M. 2008. Maroc pré-saharien. Techniques d'exploitation minière et métallurgique dans les mines d'argent, de cuivre et de plomb. In: Canto García, A. \& Cressier, P. (eds.), Minas y metallurgia en al-Andalus y Magreb occidental, Explotacion y poblamiento. Collection de la Casa de Velázquez Volume 102. Casa de Velázquez, Madrid, pp. 37-55. Essarraj, S., Boiron, M.-C., Cathelineau, M., Tarantola, A., Leisen, M., Boulvais, P. \& Maacha, L. 2016. Basinal Brines at the Origin of the Imiter Ag-Hg Deposit (Anti-Atlas, Morocco): Evidence from LA-ICP-MS Data on Fluid Inclusions, Halogen Signatures, and Stable Isotopes (H, C, O). Economic Geology 111 (7), 1753-1781.

Fauvelle, F.-X. 2018. African Archaeology and the Chalk-Line Effect: A Consideration of Mâli and Sijilmâsa. In: Green, T. \& Rossi, B. (eds.), Landscapes, Sources and Intellectual projects of the West African Past: Essays in Honour of Paulo Fernando de Moraes Farias. Brill, Leiden, pp. 46-62.

Fauvelle, F.-X., Erbati, E. \& Mensan, R. 2014. Sijilmâsa : cité idéale, site insaisissable ? Ou comment une ville échappe à ses fouilleurs. Études et Essais du Centre Jacques Berque 20, 417.

Fauvelle, F.-X., Erbati, E., Mensan, R., \& Daussy, A. 2018. The Walls of Sijilmâsa, a Medieval Islamic City in Morocco: Contribution to the Identification of Typological and Functional Variability of the Pisé Technique in Different Sectors of the Archaeological Site. In: Pradines, S. (ed.), Earthen Architecture in Muslim Cultures: Historical and Anthropological Perspectives. Brill, Leiden, pp. 37-54.

García Pulido, L.J. \& Caballero Cobos, A. 2015. Los Qanat-s de la hoya de Baza. Péndulo. Papeles de Bastitania 16, 51-73.

Grappe, J. 1976. L'ancien gisement d'argent d'Imiter (Djebel Sarhro, Maroc). Unpublished Ph.D. Thesis, Université Claude Bernard-Lyon I, Lyon.

Gratuze, B., Guerrot, C., Foy, D., Arles, A., Tereygeol, F. \& Baron, S. 2017. Les galets de verre au plomb carolingiens issus des scories de Melle : élaboration et distribution. In: Bompaire, M. \& Sarah, G. (eds.), Mines, métal, monnaie, Melle : les voies de la quantification de l'histoire monétaire du haut Moyen Âge. École Pratique des Hautes Études, Paris, pp. 87- 
110.

Guillou, J.-J., Monthel, J., Picot, P., Pillard, F., Protas, J. \& Samama, J.-C. 1985. L’Imitérite, $\mathrm{Ag} 2 \mathrm{HgS} 2$, nouvelle espèce minérale ; propriétés et structure cristalline. Bulletin de Minéralogie 108 (3), 457-464.

Hrubý, P. 2011. Jihlava - Staré Hory. Archeologický výzkum středověkého důlního, úpravnického a obytného areálu v letech 2002-2006. Unpublished Ph.D. Thesis, Univerzita Karlova, Prague.

Ibhi, A., Abia, E.H. \& Hernandez, J. 2002. Intervention des ségrégats carbonatiques dans la pétrogenèse des néphélinites à pyroxène de Jbel Saghro (Anti-Atlas, Maroc). Bulletin de la Société Géologique de France 173 (1), 37-43.

Levresse, G., Gasquet, D. \& Cheilletz, A. 2018. Le gisement argentifère d'Imiter, Anti-Atlas, Maroc. Le Règne Minéral 139, 6-21.

Milot, J., Baron, S. \& Poitrasson, F. 2018. Potential Use of Fe isotopes for Ancient NonFerrous Metals Tracing through the Example of a Lead-Silver Production Site (Imiter Mine, Anti-Atlas, Morocco). Journal of Archaeological Science 98, 22-33.

Monteil, V. 1968. Al-Bakri, routier de l'Afrique blanche et noire de Nord-Ouest. Bulletin de l'IFAN série $B$ XXX (1), 39-119.

Pasava, J. 1994. Geochemistry and the Role of Anoxic Sediments in the Origin of the Imiter Silver Deposit in Morocco. Vestnik Ceského geologického ustavu 69, 1-11.

Rico, C., Fabre, J.-M. \& Antolinos Marin, J.-A. 2009. Recherches sur les mines et la métallurgie du plomb-argent de Carthagène à l'époque romaine. Mélanges de la Casa de Velázquez 39 (1), 291-310.

Rosenberger, B. 1970a. Les vieilles exploitations minières et les anciens centres métallurgiques du Maroc, essai de carte historique-1. Revue de Géographie du Maroc 17, 71108.

Rosenberger, B. 1970b. Les vieilles exploitations minières et les anciens centres métallurgiques du Maroc, essai de carte historique-2. Revue de Géographie du Maroc 18, 59102.

Tereygeol, F. 2001. Les mines d'argent carolingiennes de Melle. Unpublished Ph.D. Thesis, Université Paris I-Sorbonne, Paris.

Wedepohl, K.H., Krueger, I. \& Hartmann, G. 1995. Medieval Lead Glass from Northwestern Europe. Journal of Glass Studies 37, 65-82. 


\section{Figures}

Figure 1

Localisation des sites miniers et métallurgiques repérés à proximité de Sijilmâsa.

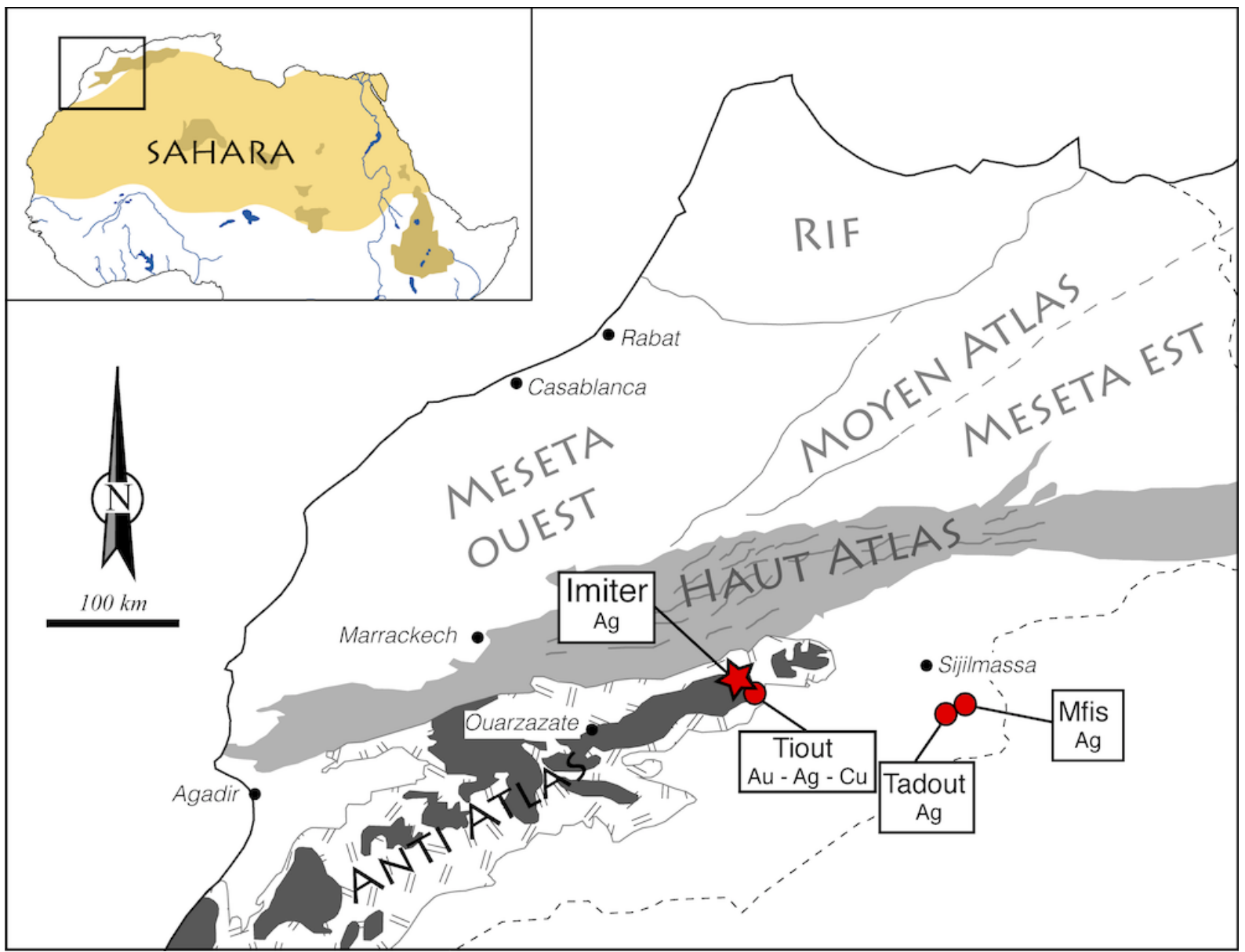


Figure 2

Carte des observations faites par El Ajlaoui (1994) sur le site d'Imiter, reprise en couleur et interprétée à la lumière des descriptions de l'auteur (Couturejuzon Colomez 2014)

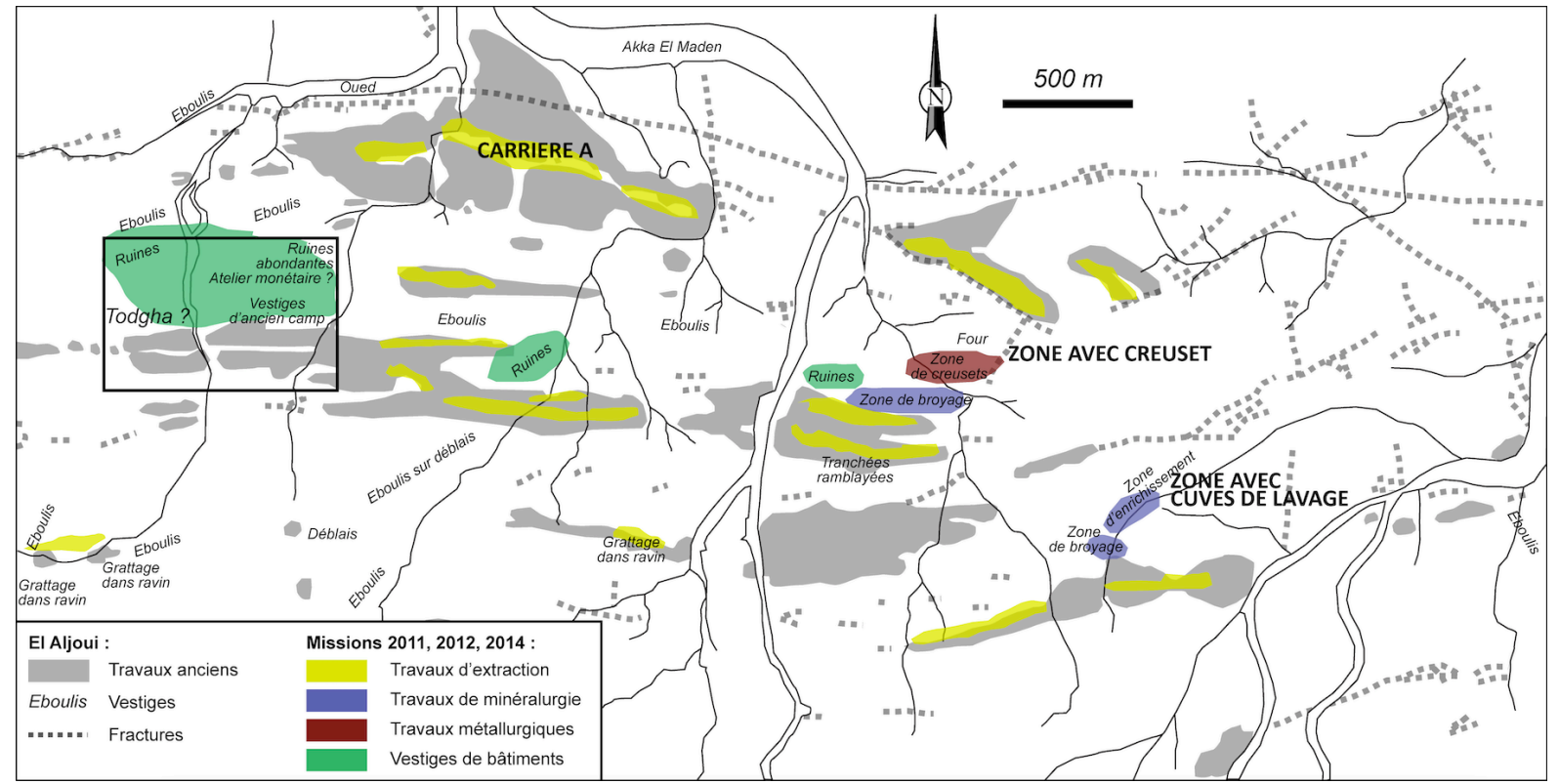

Figure 3

Carte de distribution actuelle (2011-2014) des vestiges archéologiques anciens liés aux activités minières et métallurgiques (extraction, traitement et transformation du métal) à Imiter.

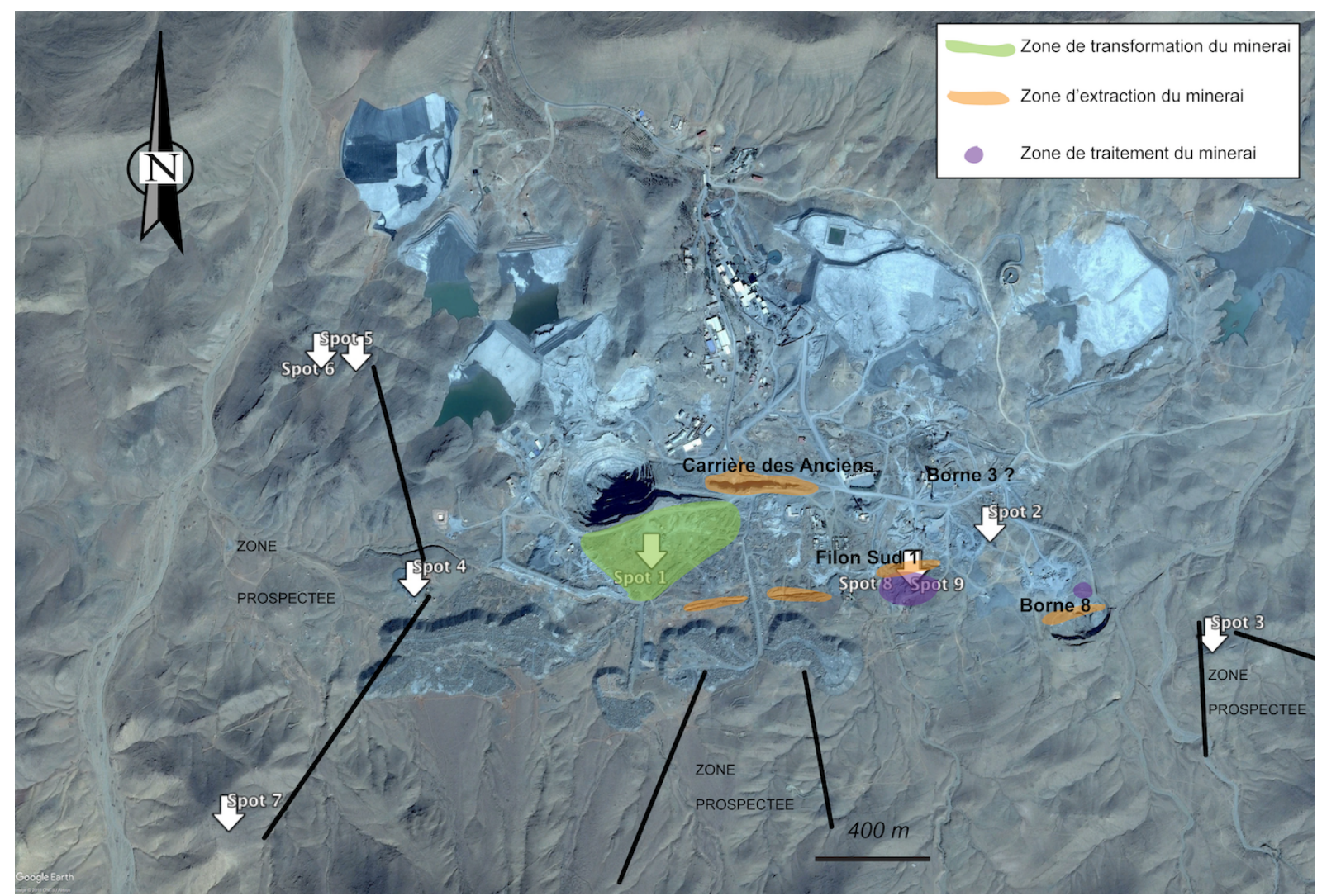


Figure 4

Vue d'ensemble de la carrière des Anciens (b) et détail (a) du parement sud de la carrière montrant des galeries et encoches.

a

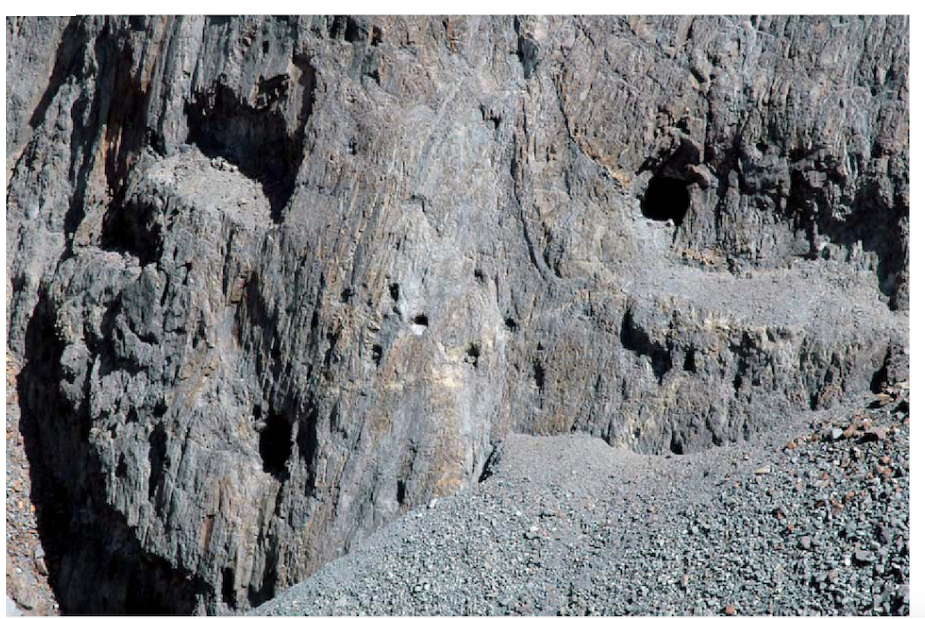

$\mathrm{b}$

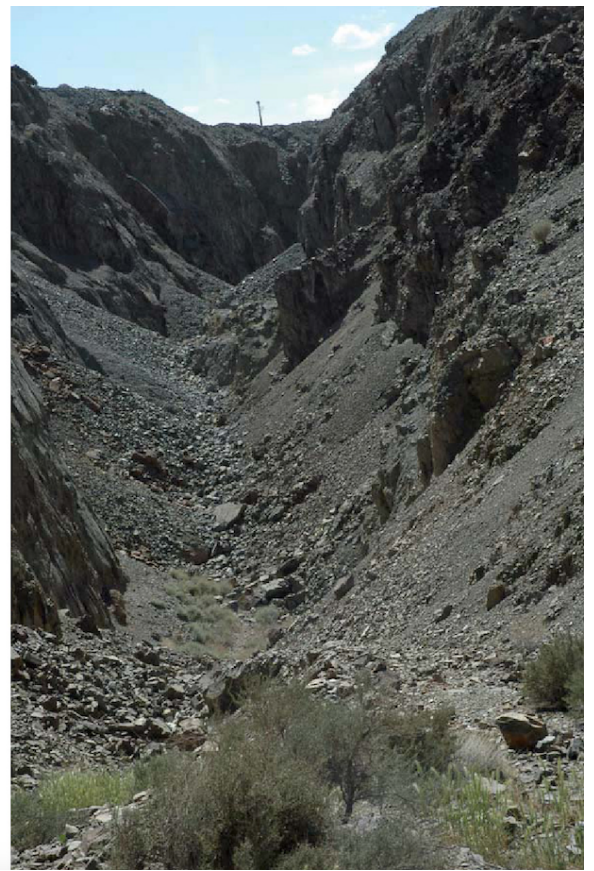

Figure 5

Coupe schématique de la partie inférieure de la paroi sud de la carrière des Anciens. Le boyau vertical est une galerie descendante (descenderie) qui relie les deux galeries; il permet de passer d'un niveau à un autre.

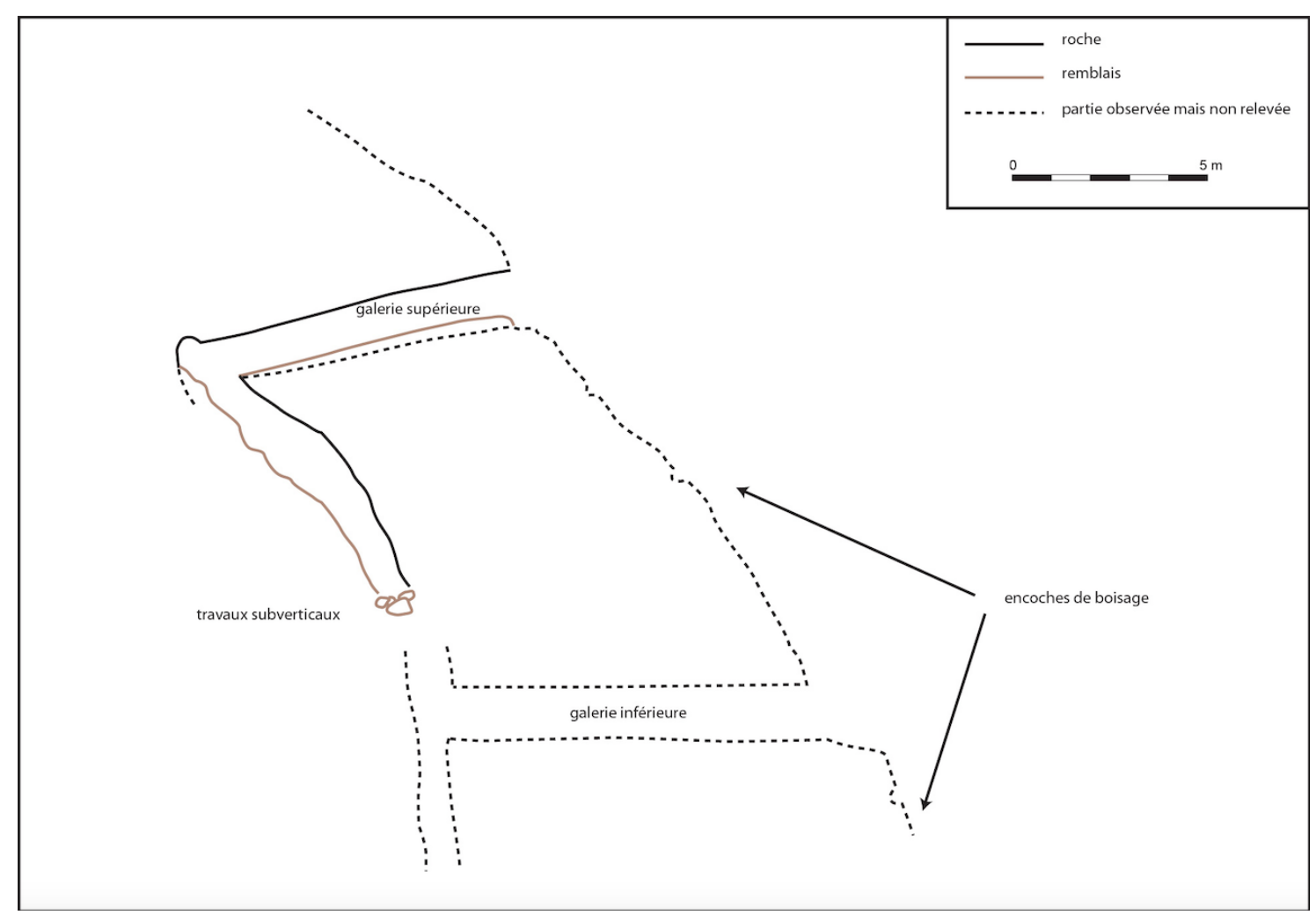


Figure 6

Galerie horizontale donnant accès au filon: vue vers le jour (a) et vue depuis le haut (b).

a

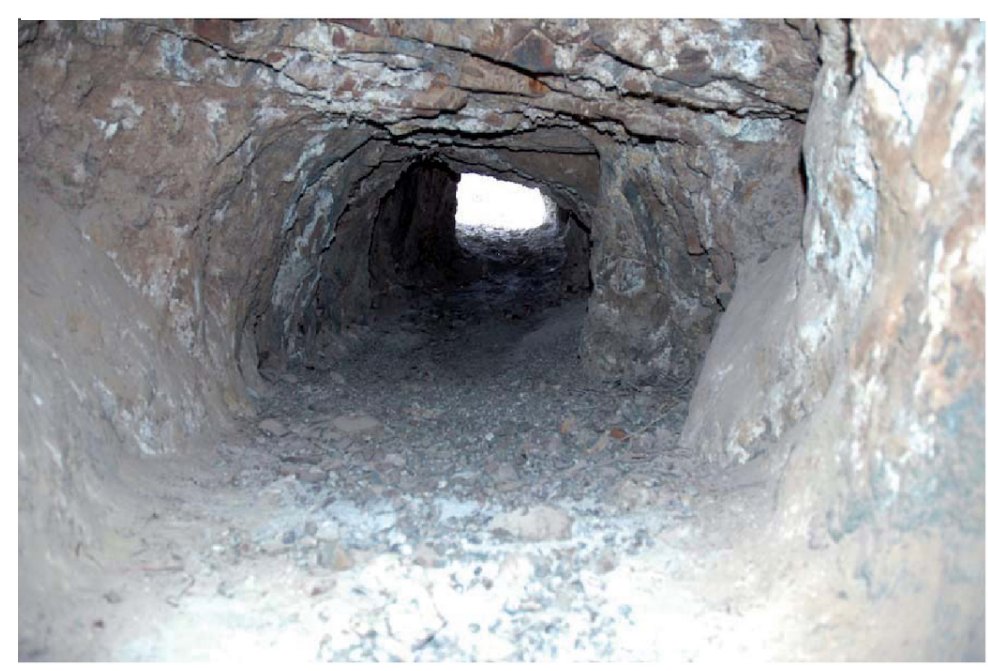

b

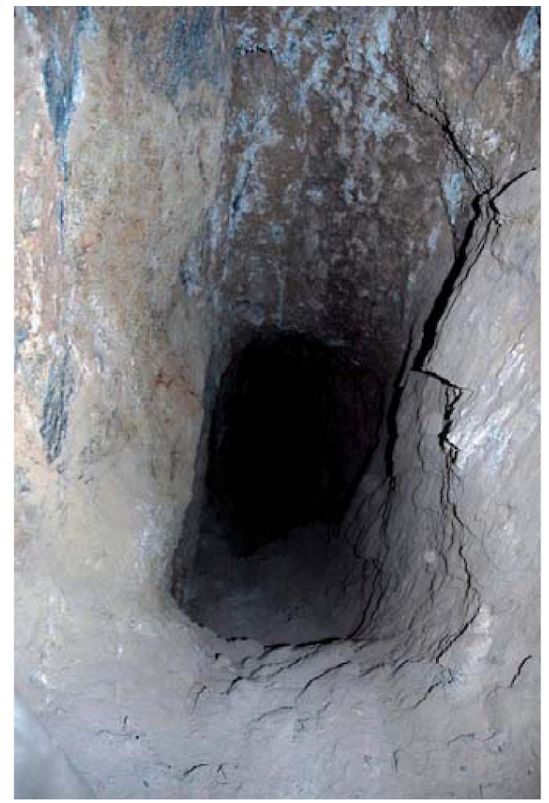

Figure 7

Coupe schématique $\mathrm{S}-\mathrm{N}$ du réseau de puits interprétée comme une galerie d'exhaure liée à la carrière des Anciens.

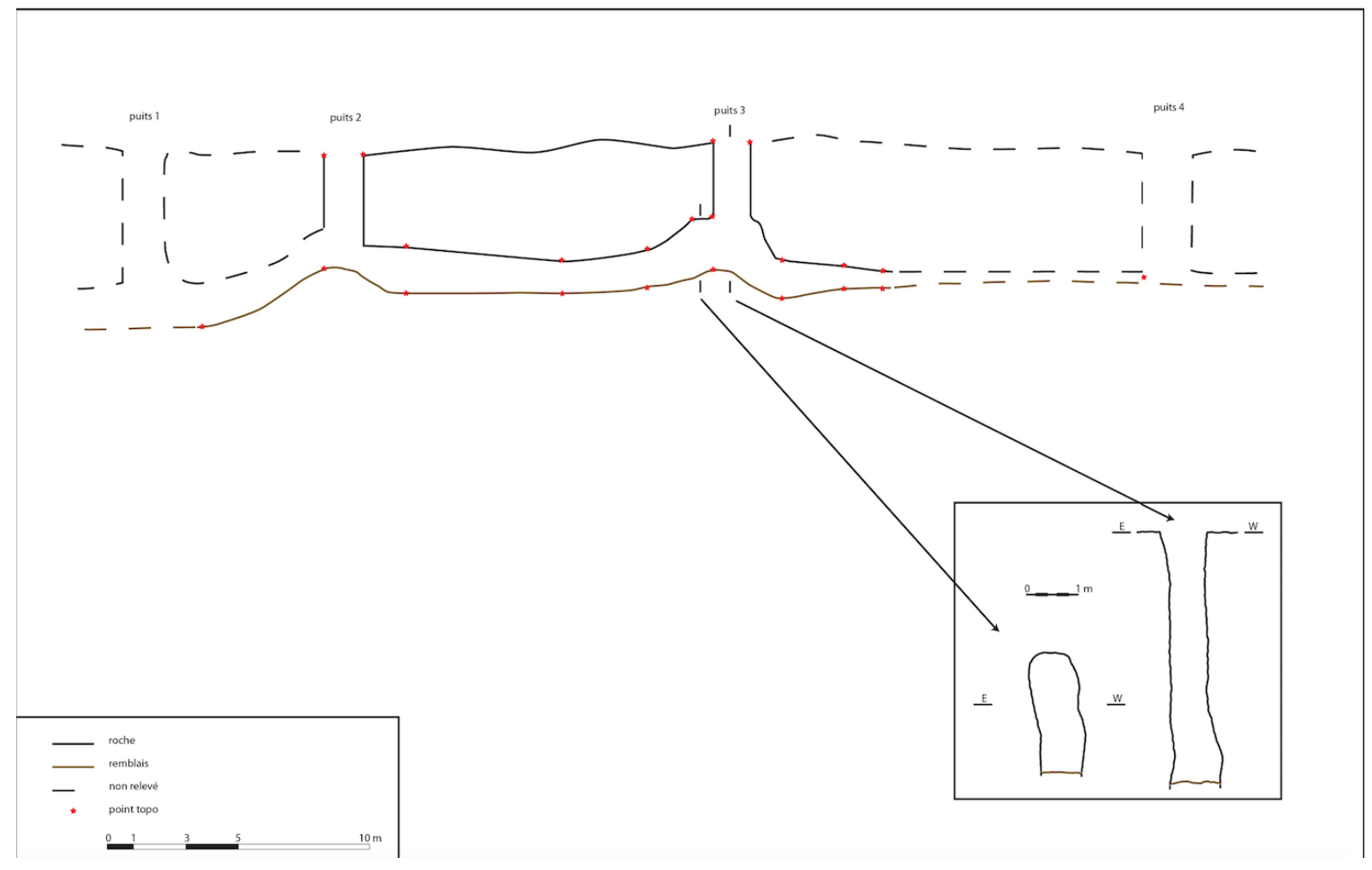


Figure 8

Puits et galerie d'exhaure liés à la carrière des Anciens.
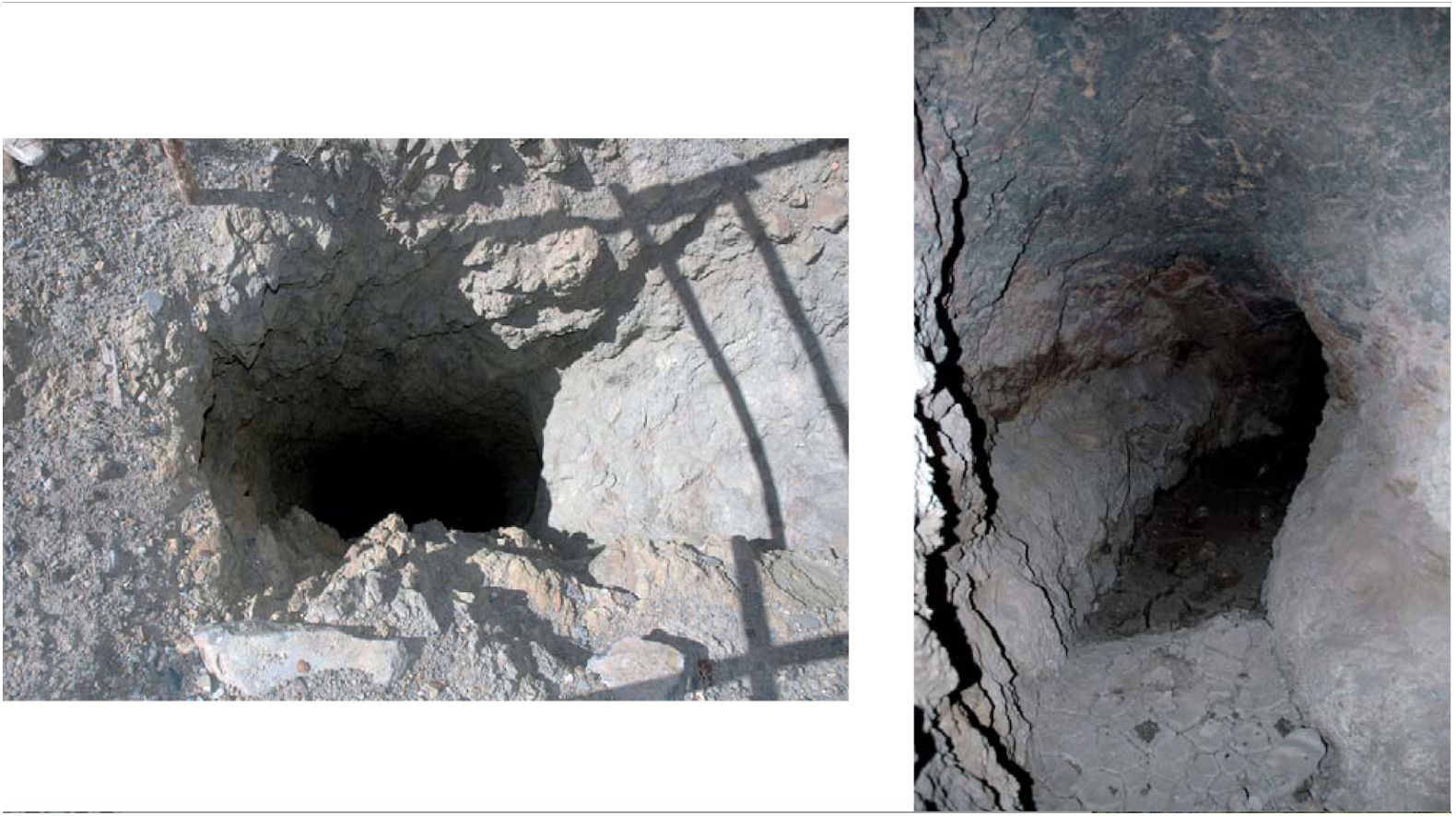

\section{Figure 9}

Succession de puits ou fosses d'extraction anciens au filon Sud 1.
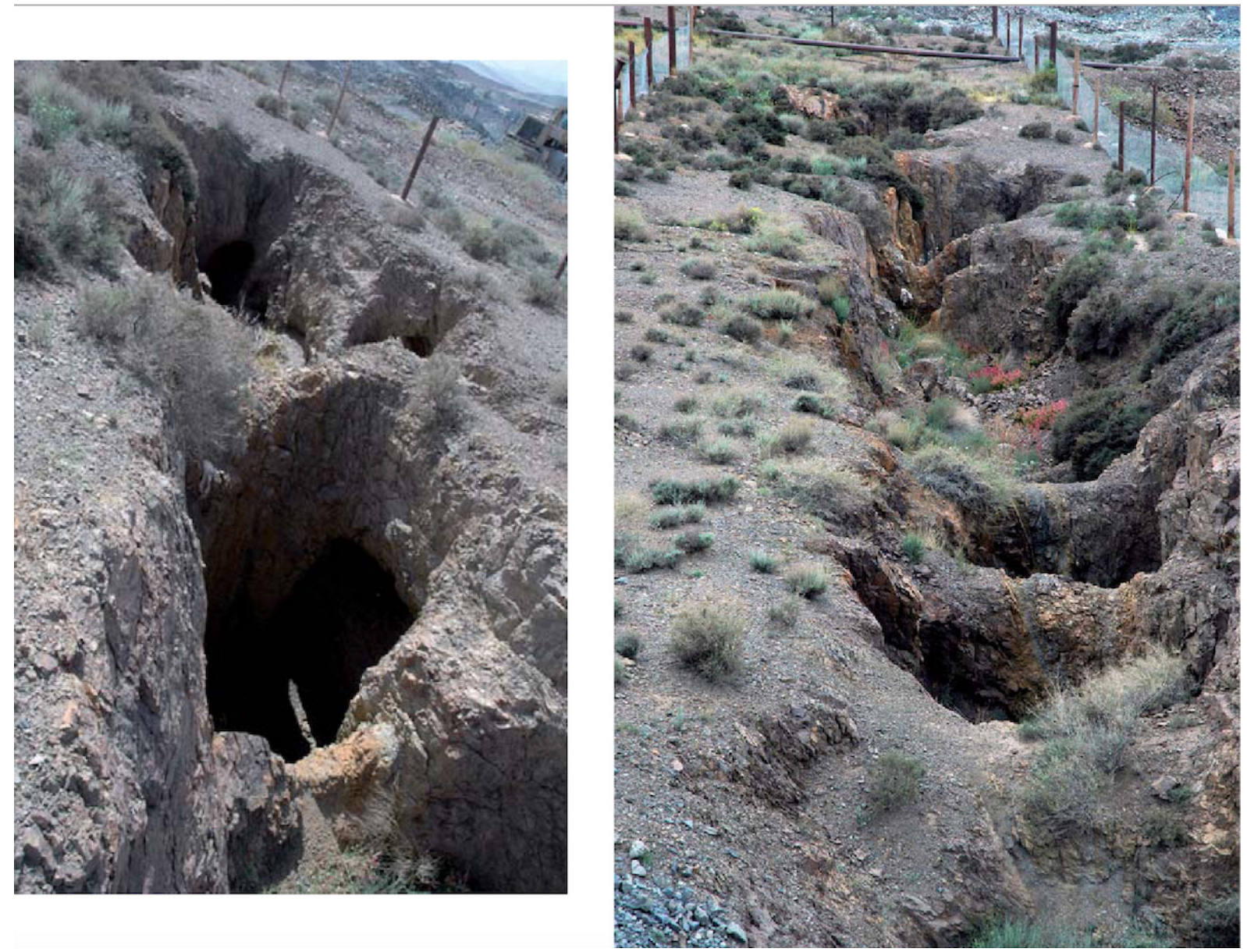
Figure 10

Relevé en plan des travaux anciens du filon Sud 1.

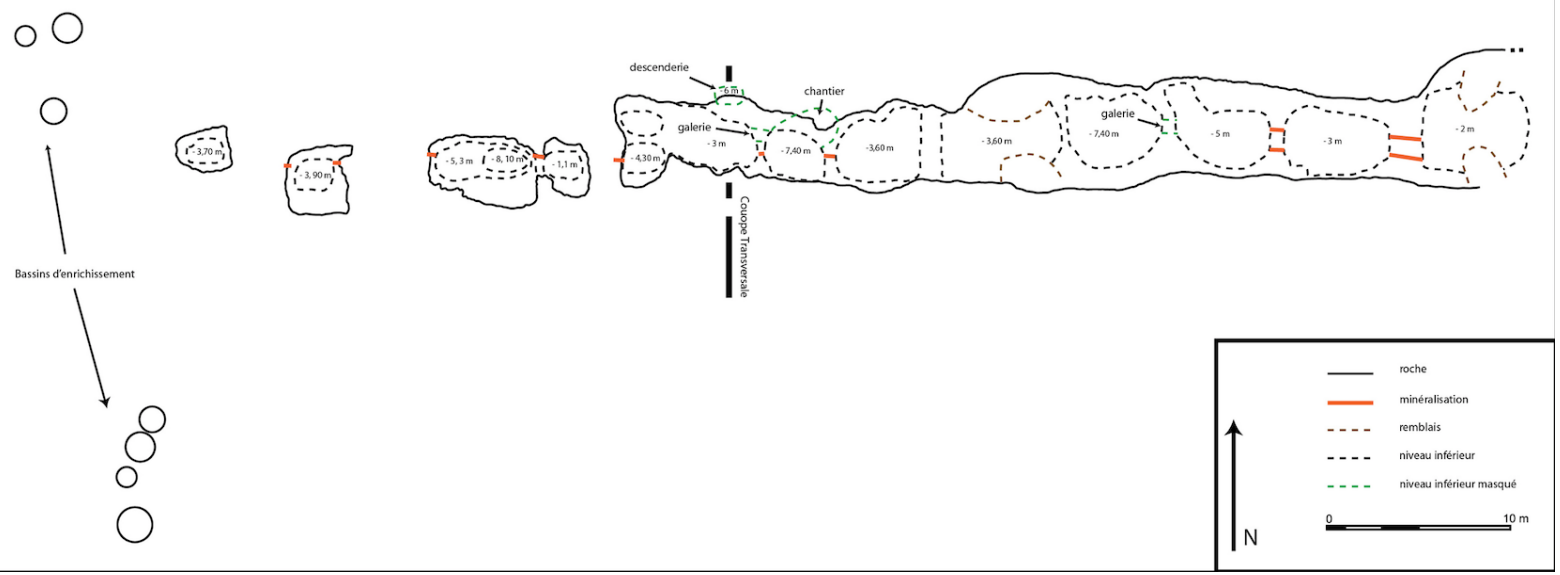

Figure 11

Coupe transversale S-N des travaux anciens du filon Sud 1.

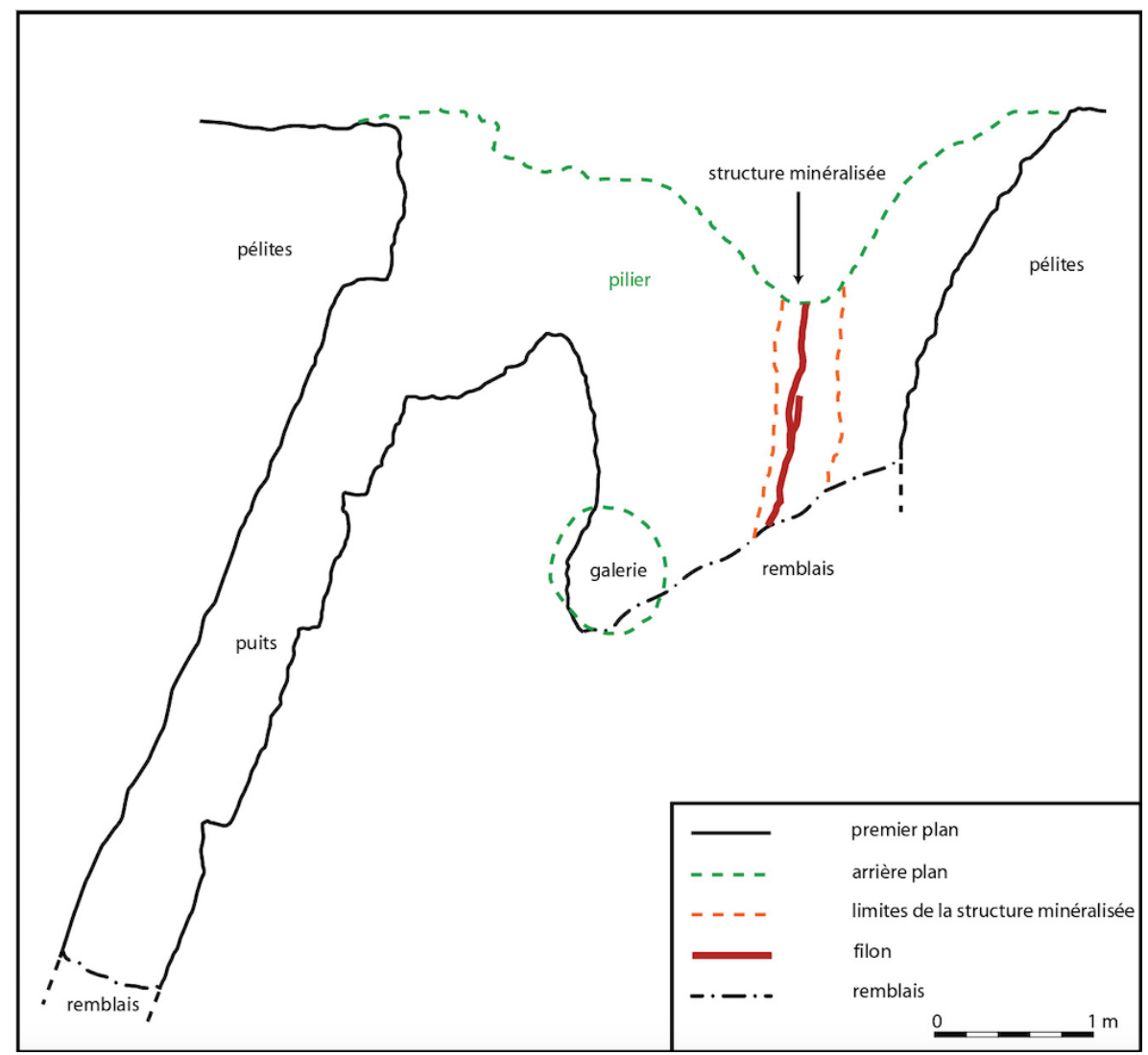




\section{Figure 12}

Vestige d'un puits et de galeries recoupés par la carrière B8.

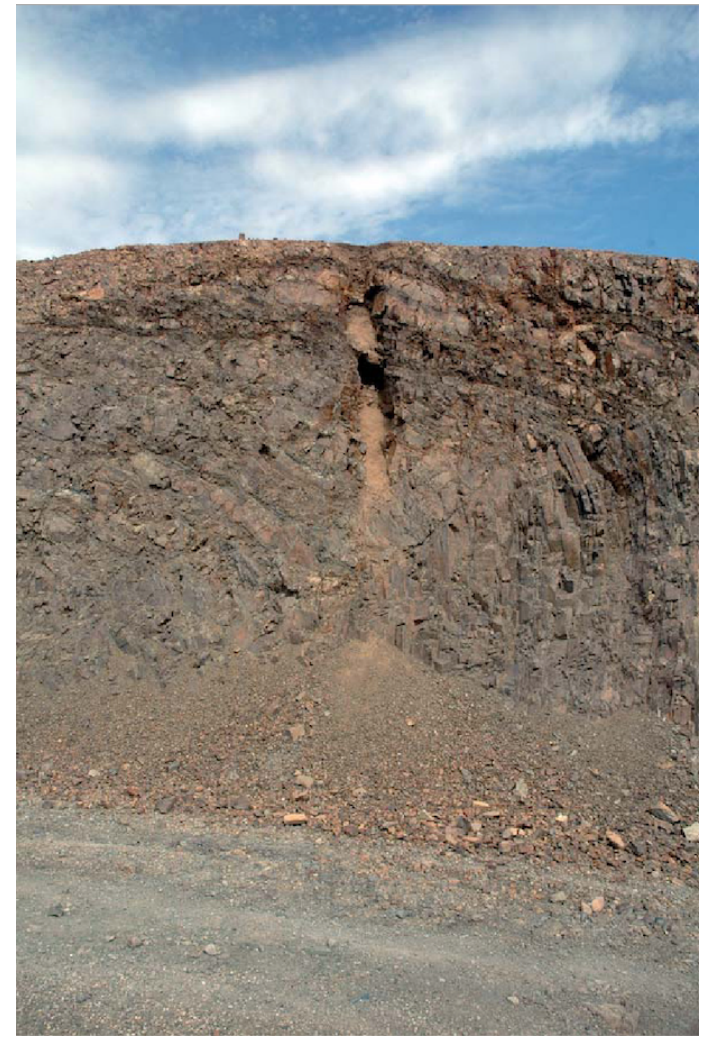

\section{Figure 13}

Alignement des « Petits puits » (a) et vue de détail (b).
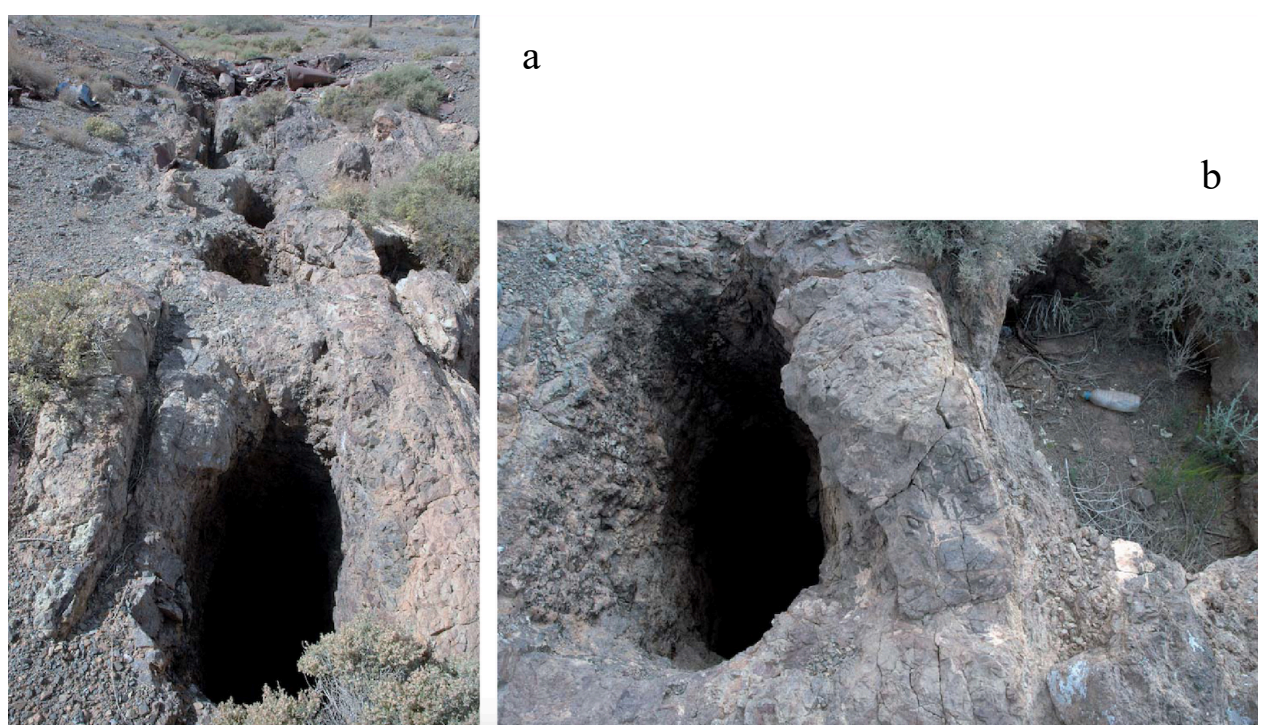
Figure 14

Relevé en plan des « Petits puits ».

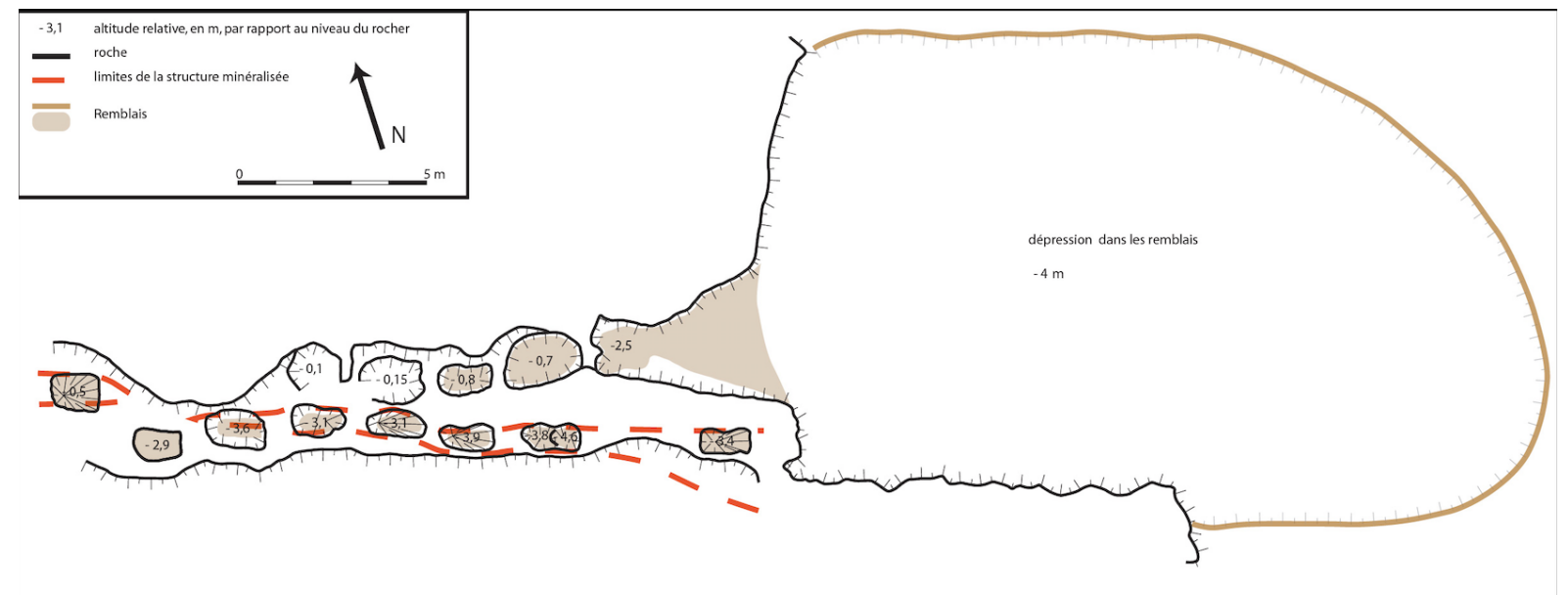

Figure 15

Dépression à l'est des « Petits puits ».

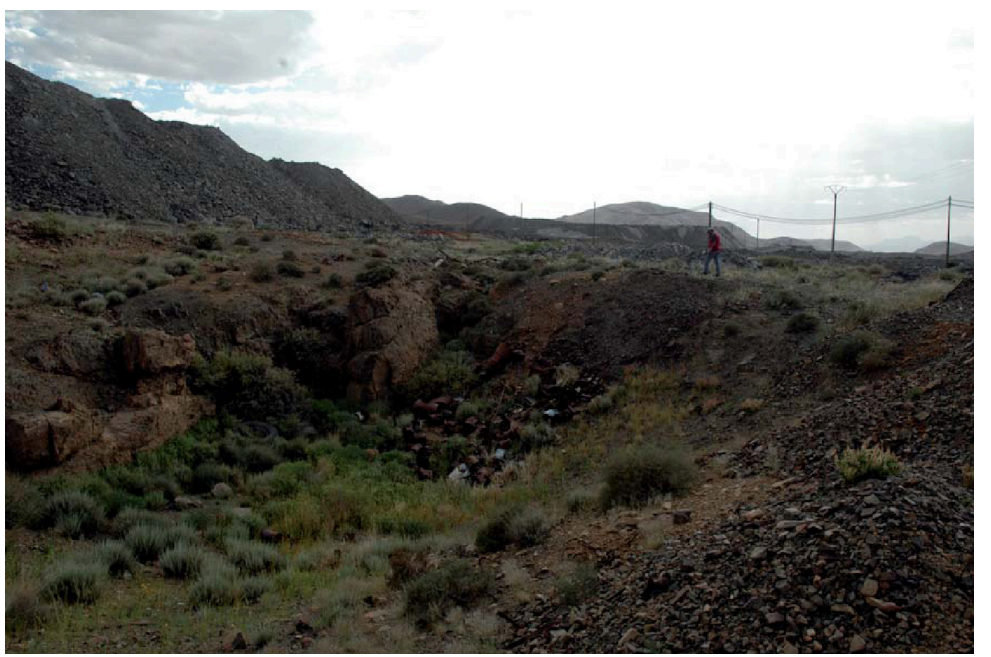


Figure 16

Fragments de meules va-et-vient et rotatives sur le site.
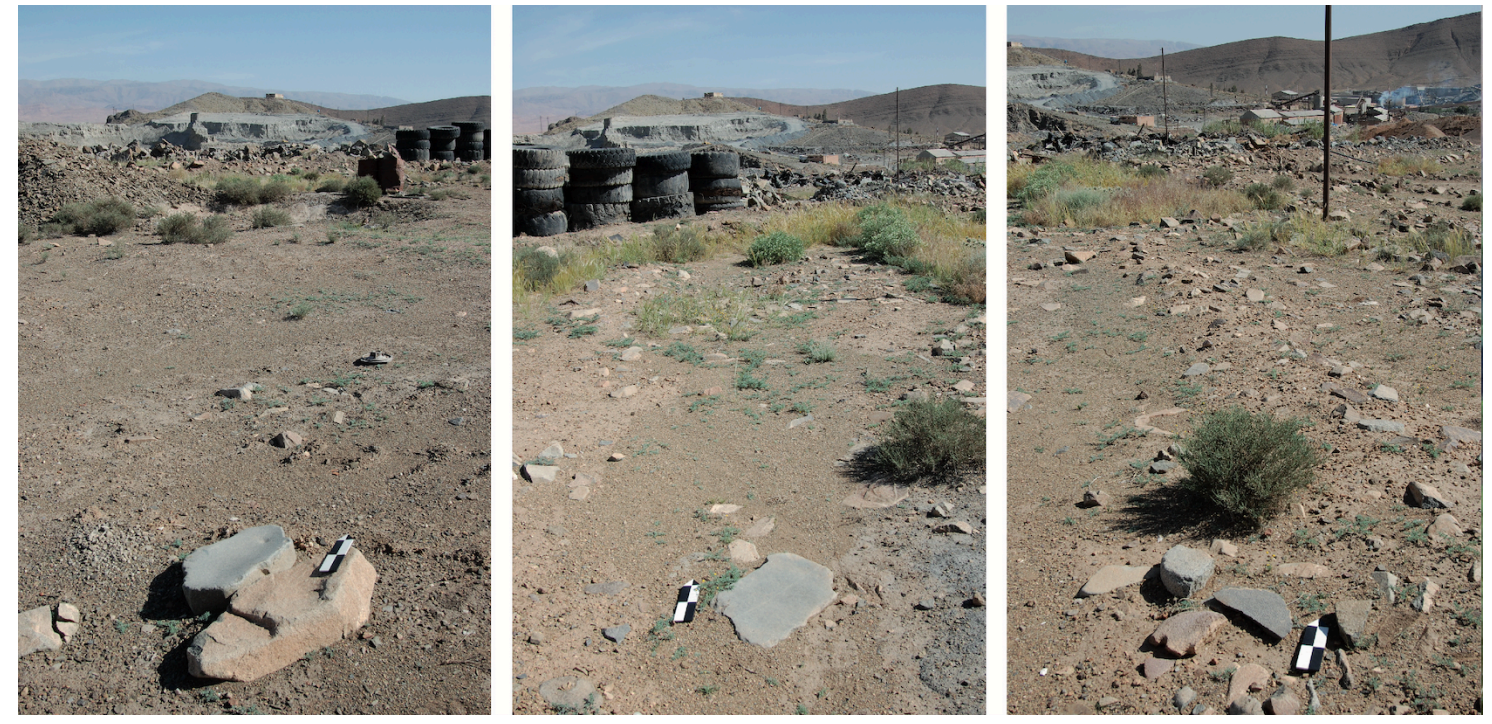

\section{Figure 17}

Meule rotative à l'entrée du Service Géologique de la mine.
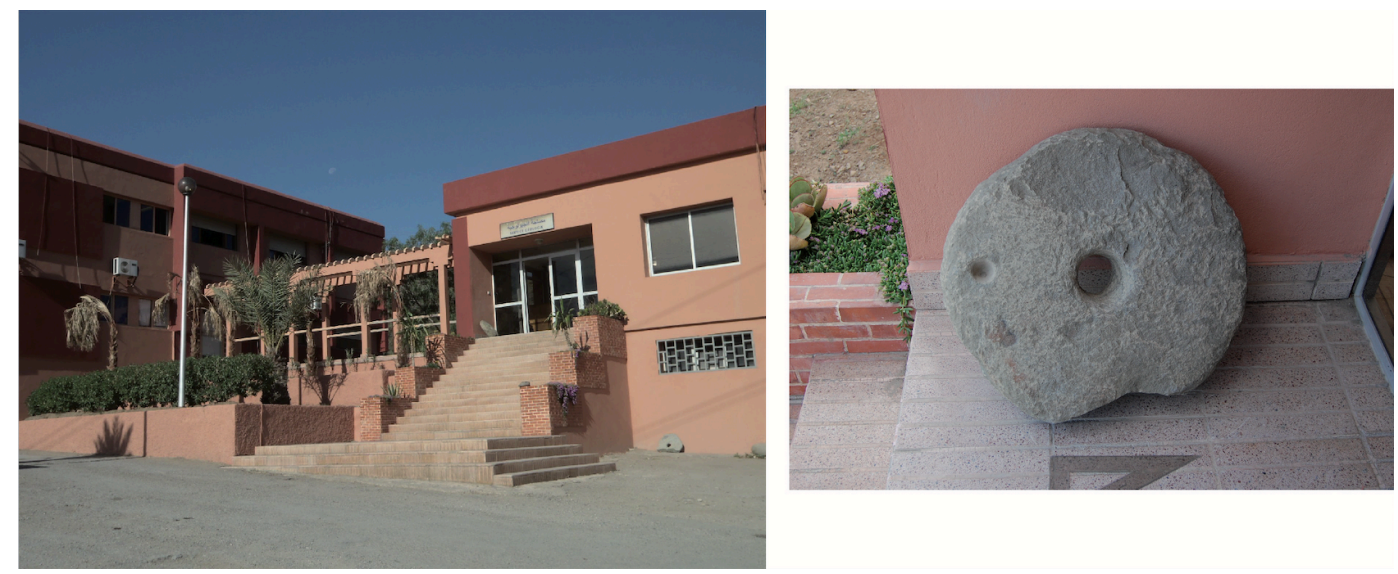


\section{Figure 18}

Échantillons de meules d'Imiter, Point 1 (en partant du haut, dans le sens horaire: granodiorite, grès, granodiorite et phonolithe).

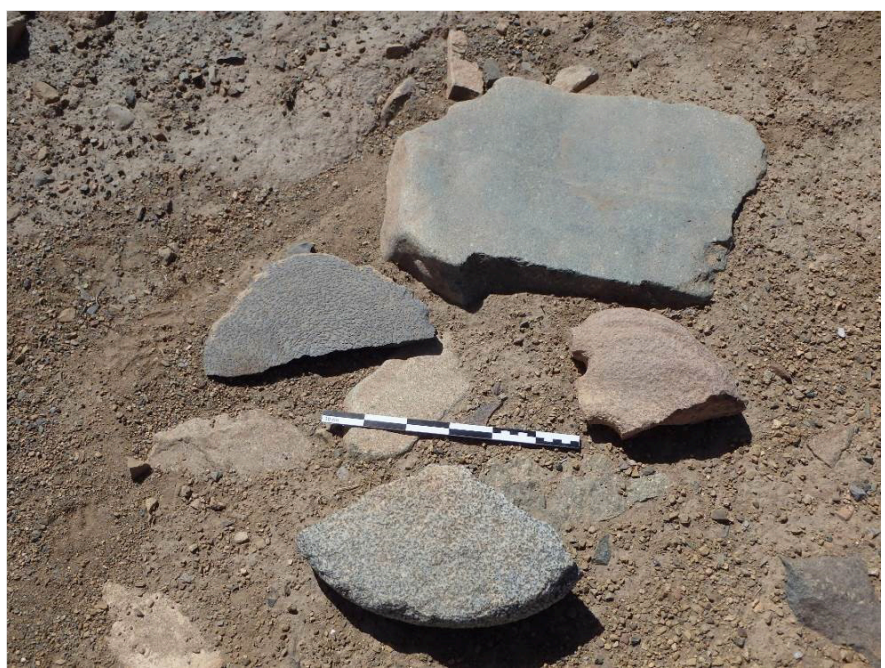


Figure 19

Gros plan de la meule en phonolithe d'Imiter (a) et d'un spécimen similaire sur le site de Sijilmâsa (b).
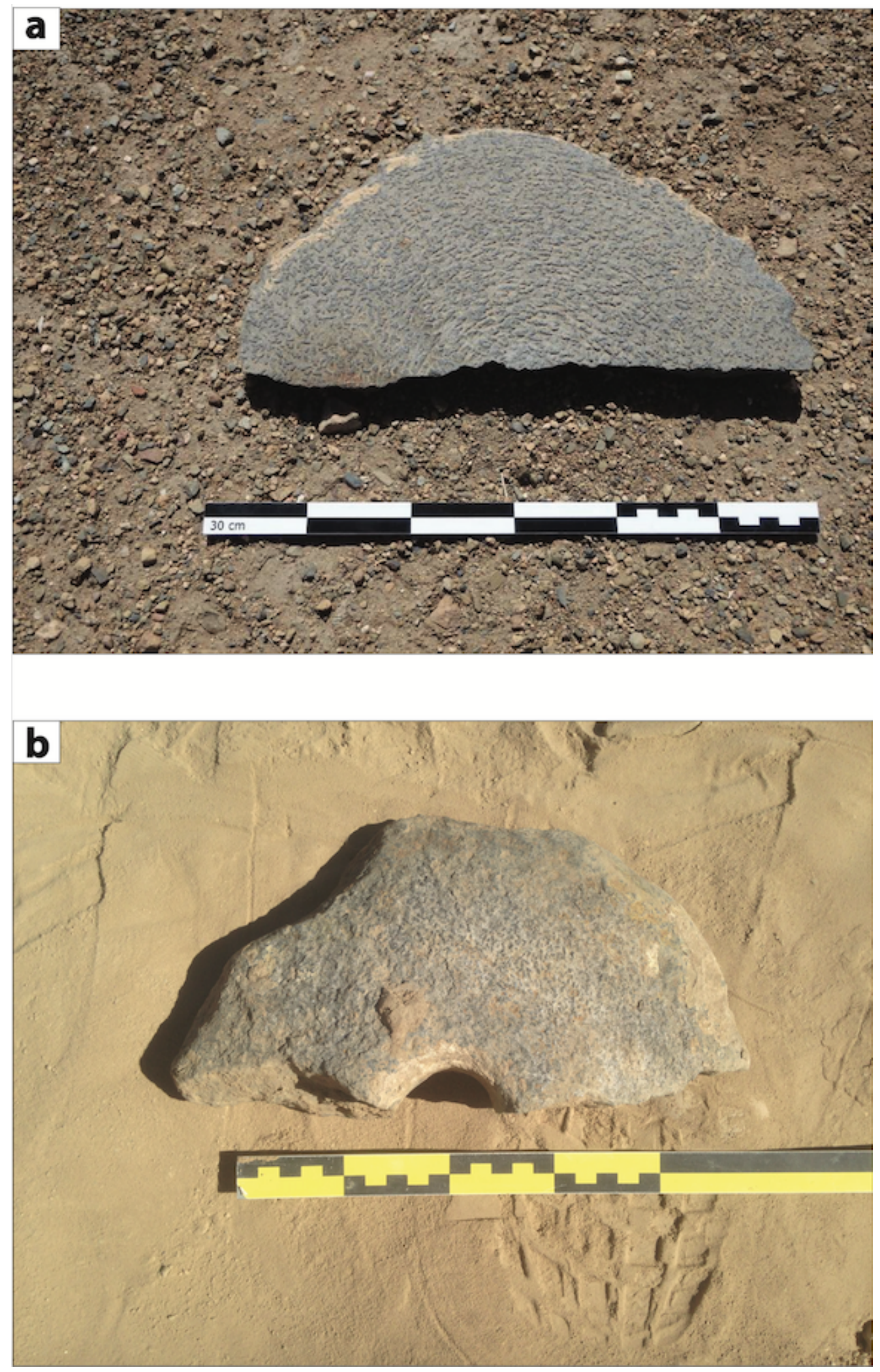
Figure 20

Affleurement du banc de phonolite et détails du faciès. On observe aisément les phénocristaux de feldspaths alcalins.

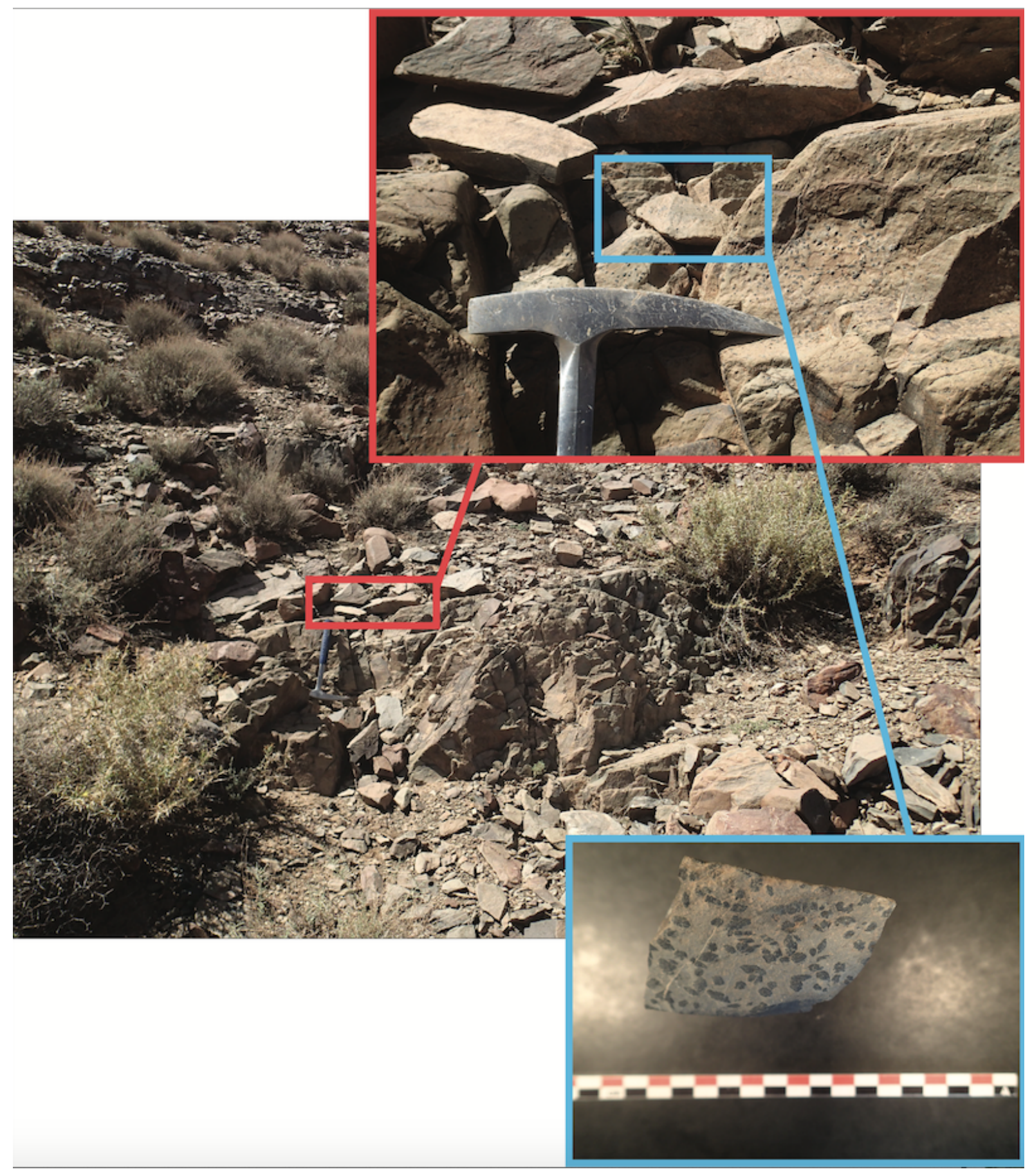


Figure 21

Meule à cupules (a) et spécimen d'outil lithique en lien avec le traitement du minerai à Imiter

(b). Ici, il s'agit de la face ayant servie de percuteur.
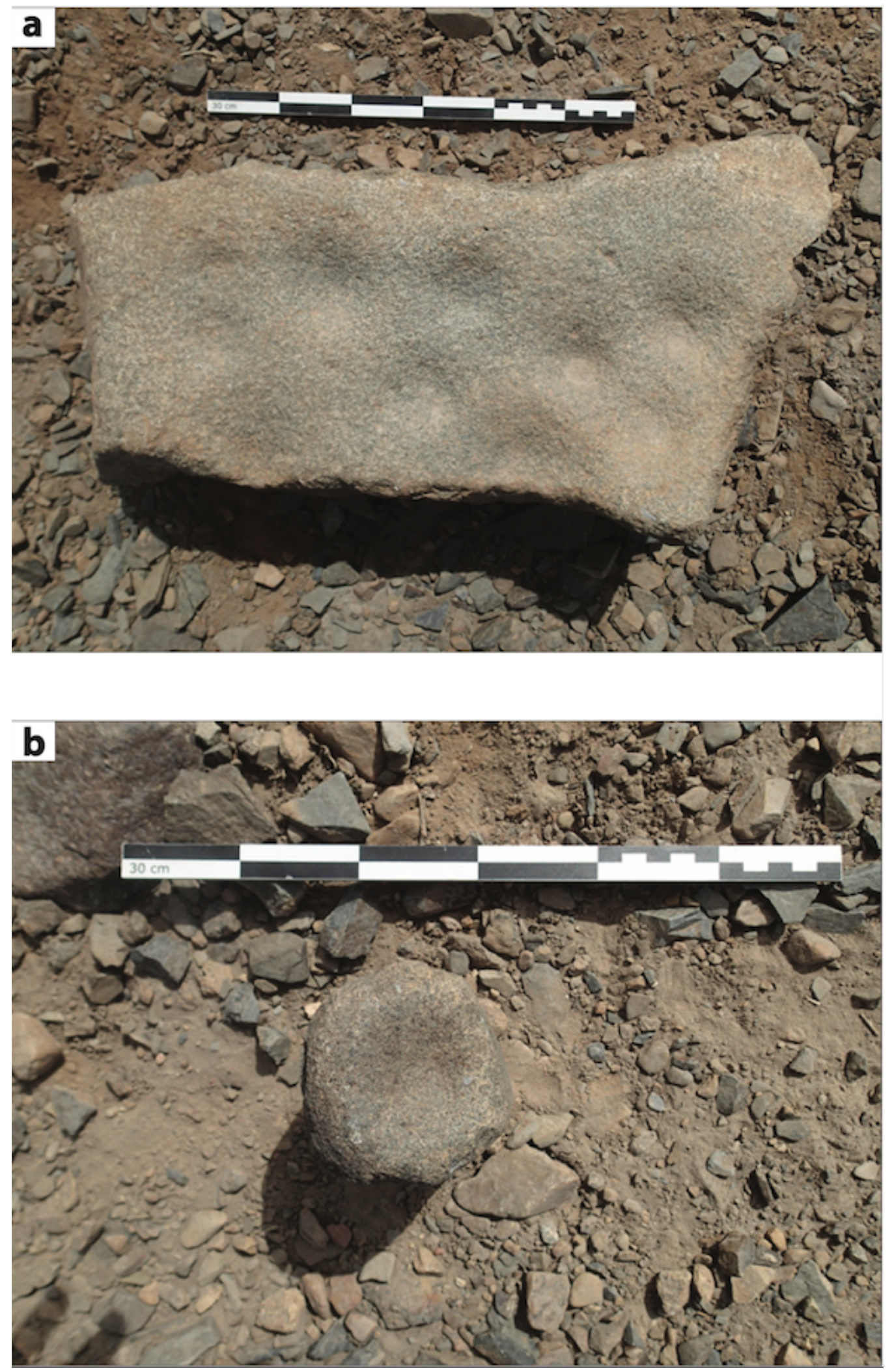


\section{Figure 22}

Cuves d'enrichissement A et B (sondages archéologiques et état de visibilité des structures).
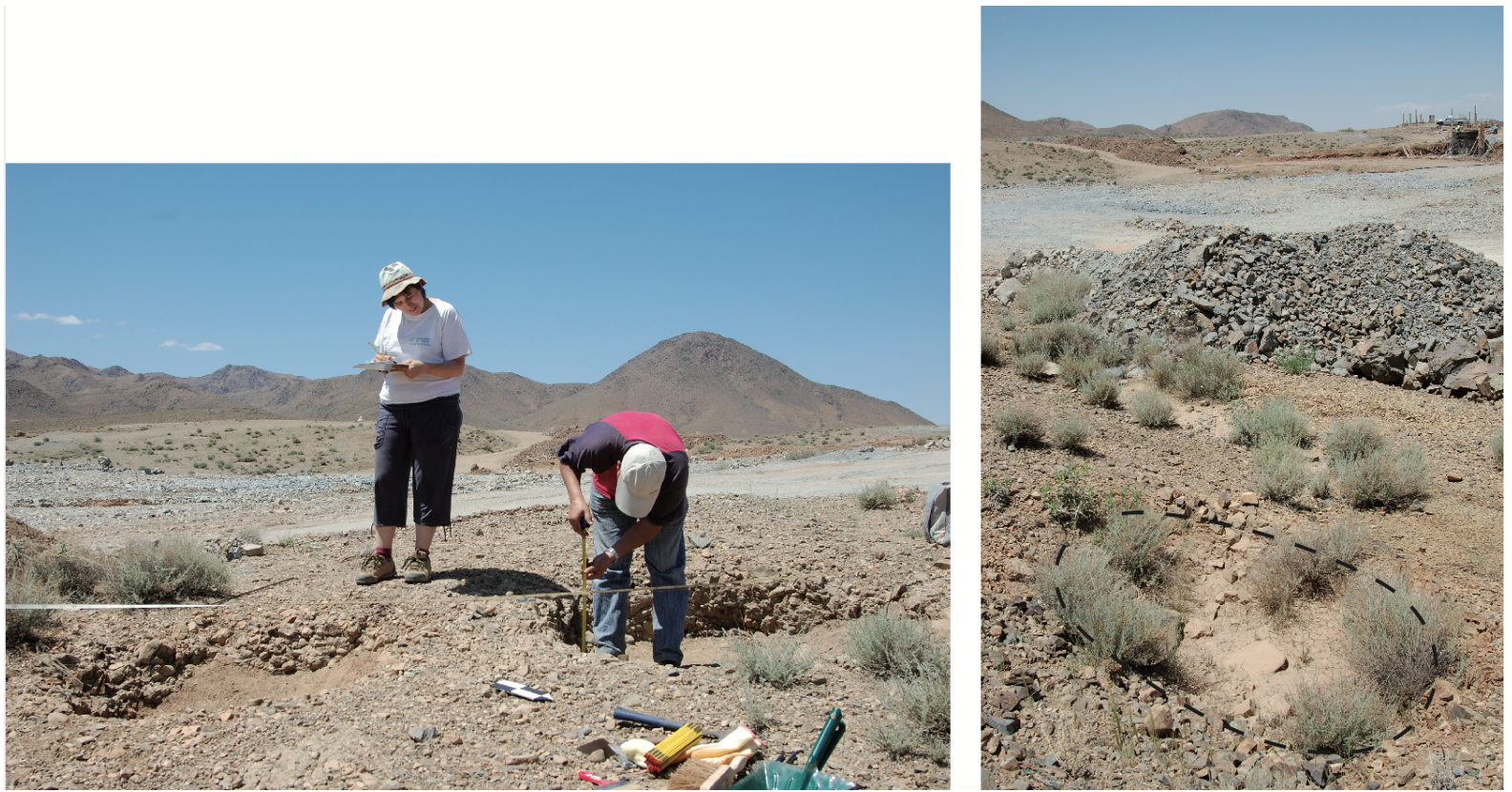

Figure 23

Relevé des Cuves A et B.

A

B

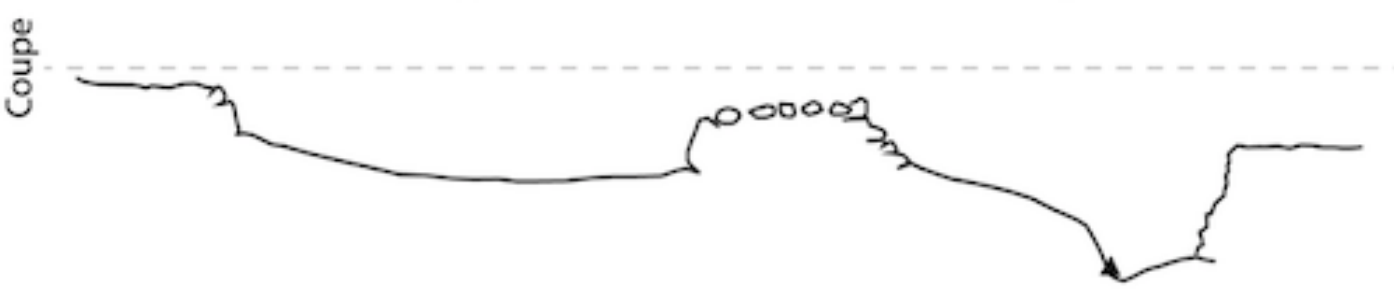

Cendre
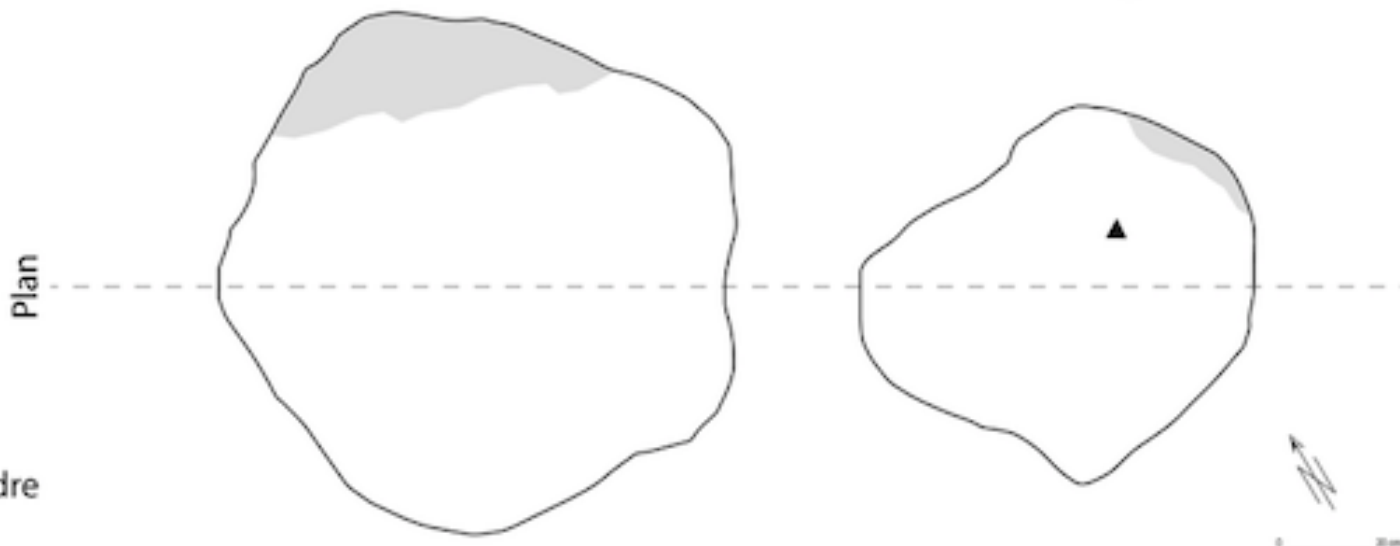

A $\mathrm{C} 14$

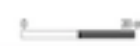




\section{Figure 24}

Vue zénithale de la cuve $\mathrm{C}$ en fin de fouille et gros plan du micro-sondage au travers du revêtement de la structure, montrant le parement de blocs de schiste horizontaux.

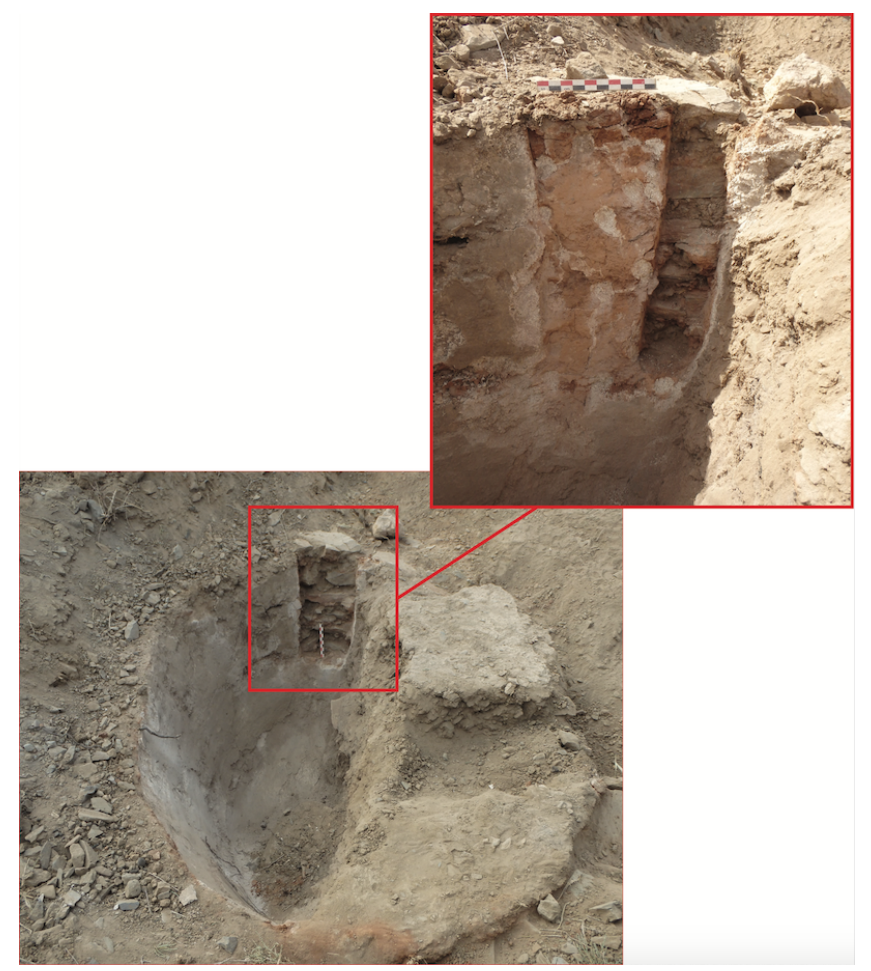

Figure 25

Relevé en plan et coupe de la cuve C.

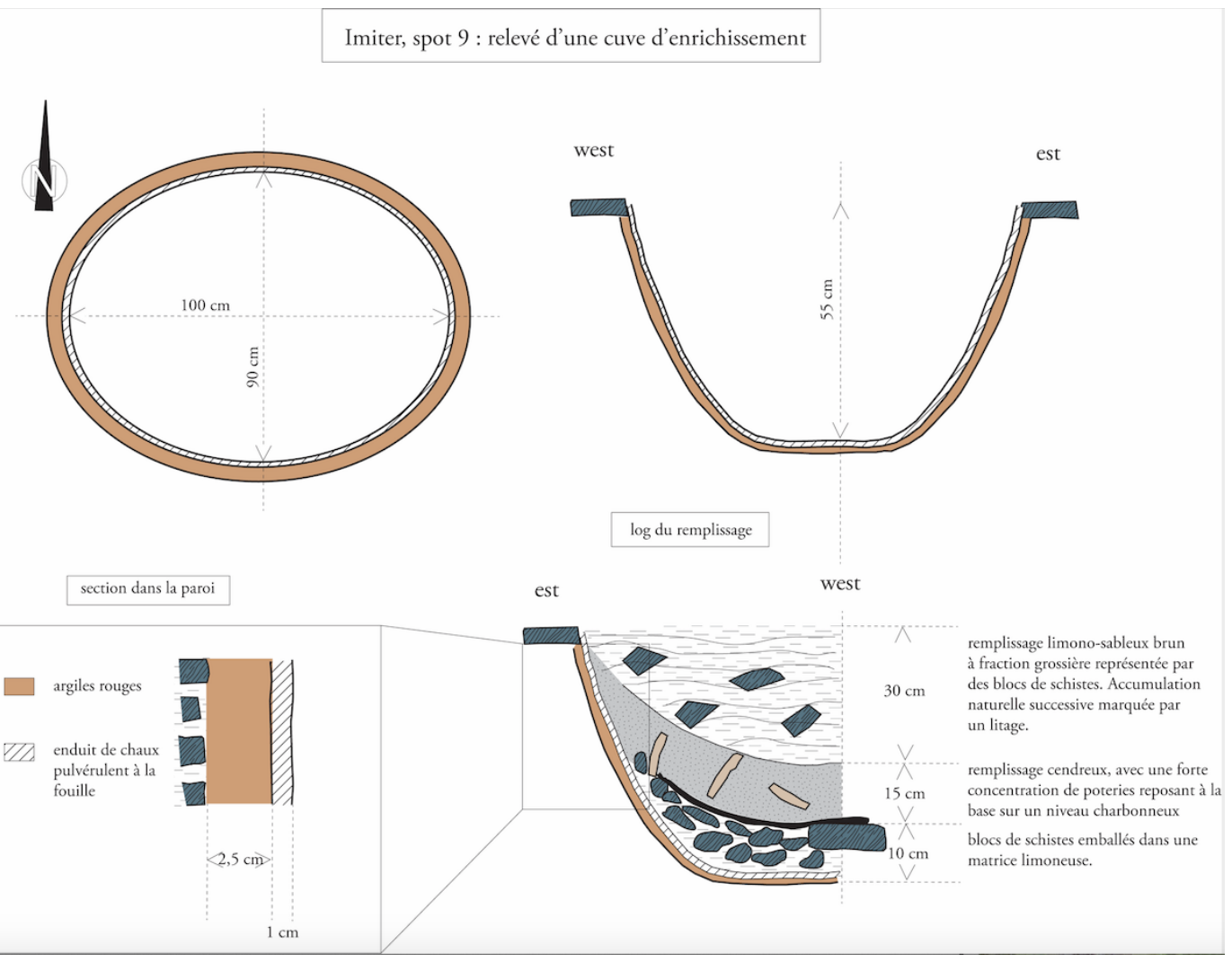


Figure 26

Bassins en haut du thalweg.

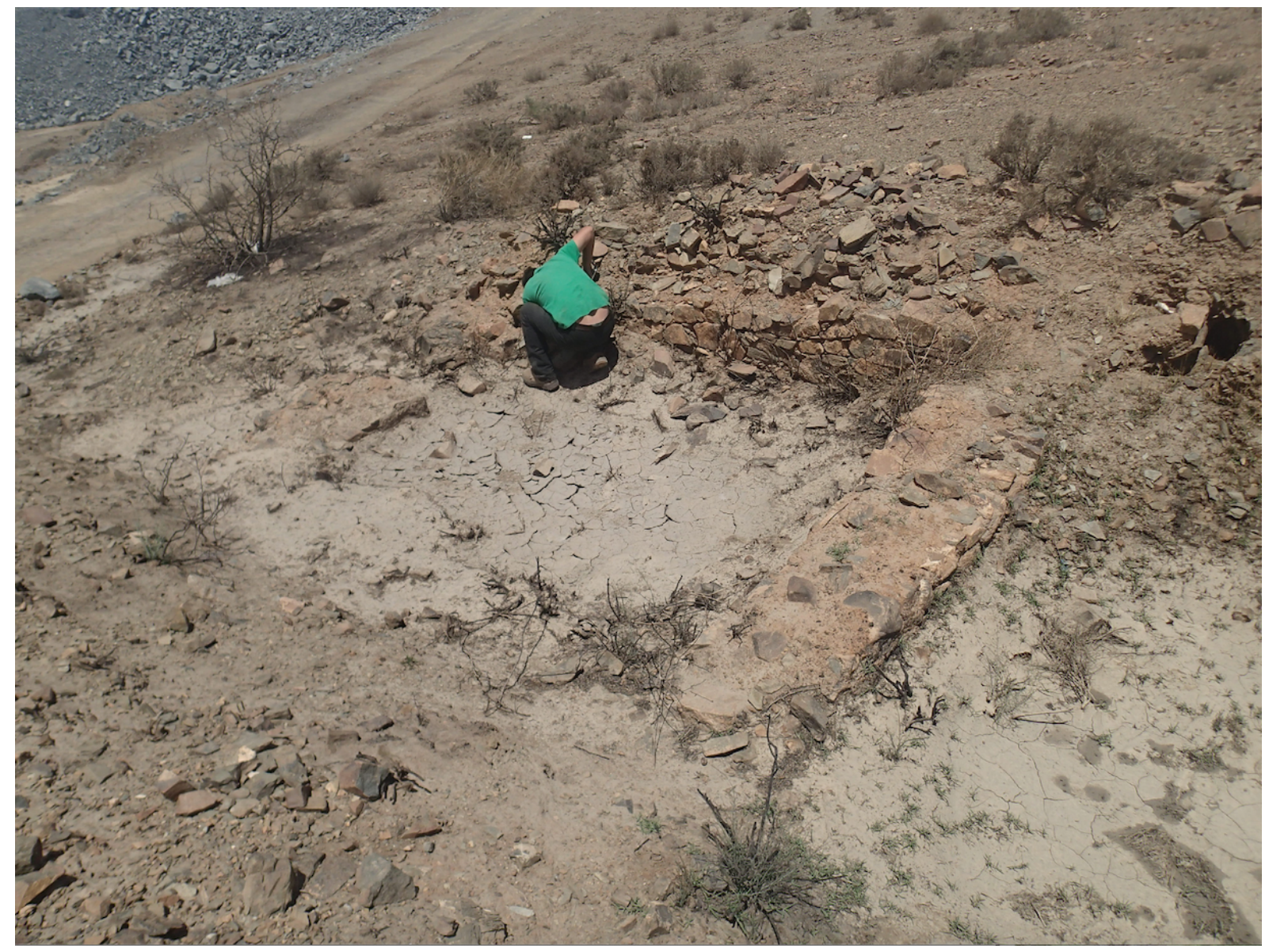

Figure 27

Creusets d'Imiter (El Ajloui 2008: 53).

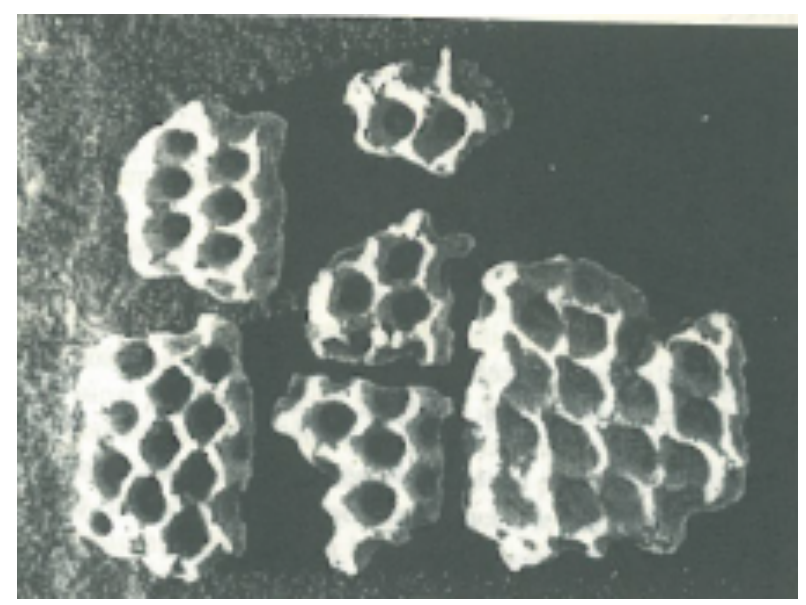


Figure 28

Légende : Aspect macroscopique des 2 types de scories anciennes rencontrées à Imiter. En haut et au milieu, scories appartenant au type 2. Elles sont massives avec une texture vitreuse, de couleur noire avec des reflets rougeâtres pour certaines. En bas, scorie appartenant au type 1. Massive également, aspect fibreux, de couleur noire et sans reflet. Malgré un aspect macroscopique différent, ces scories présentent des compositions minéralogiques comparables. Pour plus de détails minéralogiques et chimiques (élémentaires et isotopiques) sur ces scories, voir Milot et al., 2018.
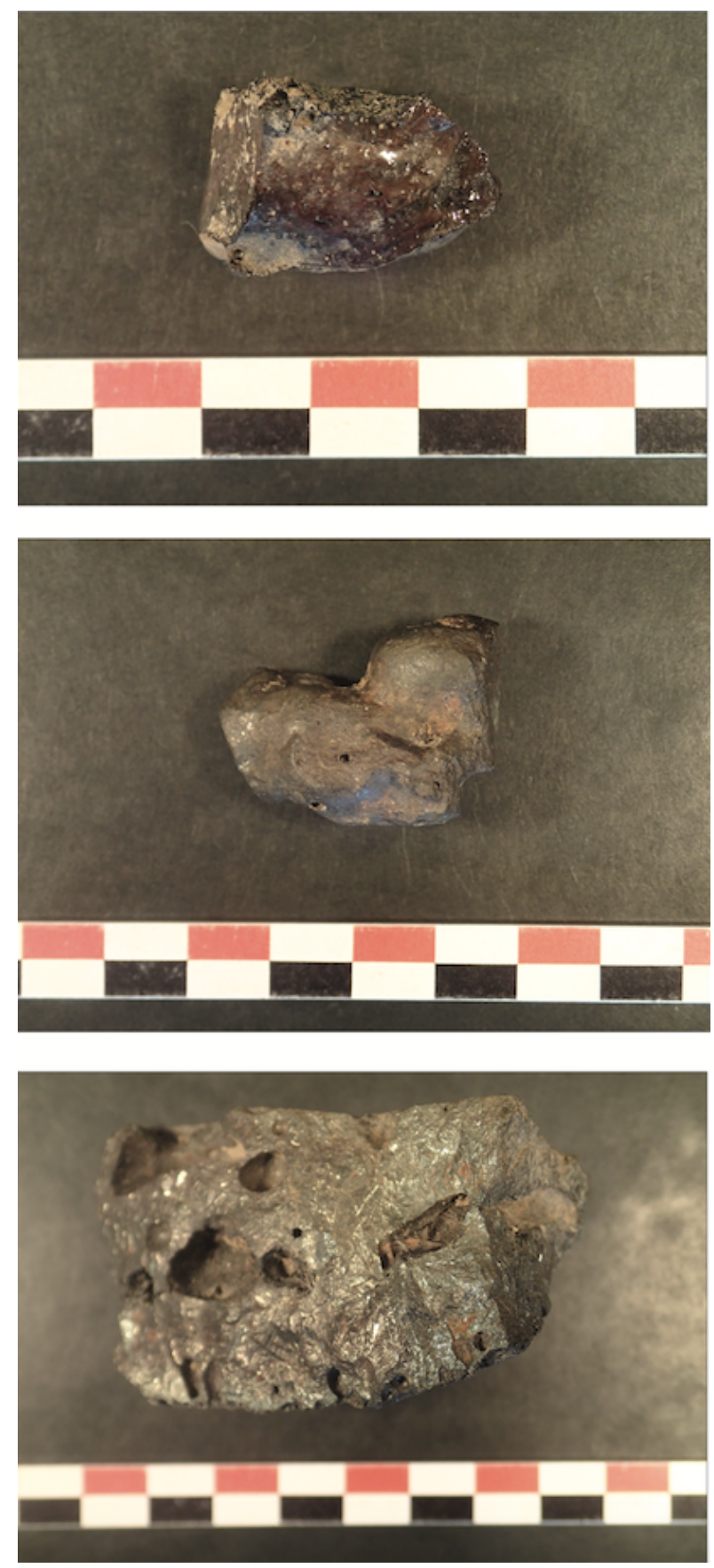
